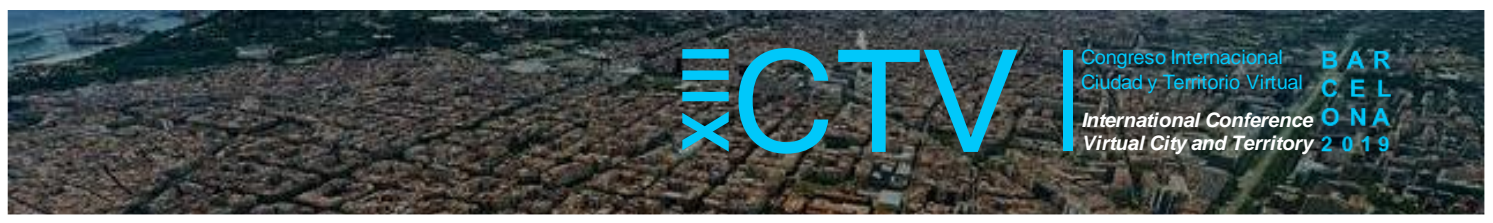

\title{
LA RESISTENCIA DEL SUELO, EL PAISAJE INVISIBLE
}

\author{
Martínez Hidalgo, Celia ${ }^{1 *}$; Skotheim, Marja F. ${ }^{2}$; Sjodahl, Elisabeth ${ }^{3}$ \\ Remisión inicial: 2019-06-25; Remisión definitiva: 2019-07-17; Publicación: 2019-12-21
}

Citación: Martínez Hidalgo, C. et al. (2019). La resistencia del suelo, el Paisaje Invisible. En XIII CTV 2019 Proceedings: XIII International Conference on Virtual City and Territory: "Challenges and paradigms of the contemporary city": UPC, Barcelona, October 2-4, 2019. Barcelona: CPSV, 2019, p. 8699. E-ISSN 2604-6512. DOI http://dx.doi.org/10.5821/ctv.8699

\section{Resumen}

Del proyecto de saneamiento al proyecto urbano. Los procesos de creación o remodelación urbana deben ayudar a mitigar los efectos del cambio climático, moderando la subida de la temperatura del planeta y el despilfarro de recursos energéticos e hídricos. Se trata de sustituir la actual recogida de pluviales, que busca la rápida evacuación, por un sistema visible basado en la naturaleza (NBS), una infraestructura paisajística capaz de retener, infiltrar, transportar el agua generando un nuevo paisaje de cohesión urbana y territorial. Esta infraestructura verde busca gestionar el riesgo, aumentando el grado de resiliencia del territorio, permitiendo que éste se inunde allí donde la presencia temporal del agua no produzca daños o incluso sea beneficiosa. Trabajar en el diseño conjunto de espacio urbano vivido y la infraestructura de recogida y evacuación del agua requiere de un cambio de paradigma, donde la incertidumbre, lo dinámico y la gestión del riesgo sean materiales de proyecto.

La resistencia al cambio del subsuelo. Basándonos en la experiencia desarrollada dentro del Plan especial del parque fluvial del Kjørbekk y la regulación urbanística del ámbito, para el Ayuntamiento de Skien (Noruega; surgido de la problemática generada por el riesgo de rotura de la tubería subterránea encargada de evacuar las aguas del arroyo Kjørbekk y de las pluviales de su cuenca ocupada por una periferia suburbana, podemos afirmar que la gestión de las escorrentías, no es tan sólo un problema de caudales máximos y secciones hidráulicas, se trata de cohesionar el plano visible de la ciudad con la complejidad del subsuelo invisible (instalaciones eléctricas, rellenos contaminados, terrenos expansivos, etc.).El urbanismo se ha encargado de legislar y dibujar el plano de lo visible pero poco o nada dice sobre el subsuelo. Es necesario realizar un trabajo de "arqueología contemporánea" para trazar las líneas de agua, distribuir las zonas de retención e infiltración evitando la difusión de la contaminación, localizar las redes existentes (fibra, eléctricas, etc.) y fijar las cotas de las conexiones para poder construir un sistema de drenaje abierto en la cuenca.

Gestionando la incertidumbre. Del plan al proyecto. Superado el problema de la arqueología de lo subterráneo se llega a otro desafío de dimensiones aún más grandes; la transformación del funcionamiento de la infraestructura existente junto al nuevo proyecto. En el caso de Kjørbekk habia que elevar de cota de evacuación de agua de toda una cuenca hidrográfica (consecuencia de traer a la superficie el río soterrado en la tubería a $15 \mathrm{~m}$ de profundidad), con una intervención mínima del tejido existente. Los problemas que surgen de re-conexión entre el arroyo y la red existente podrían originar una obra de una envergadura imposible de afrontar para un ayuntamiento del tamaño de Skien. Habitualmente un proyecto de saneamiento se planifica para ejecutar en un plazo de tiempo acotado, y por pocos actores. En el caso de Kjørbekk se hizo necesario diseñar un proceso de transformación en el tiempo, más que un proyecto de ejecución aislado. Por ello la idea de plan estratégico que defina una idea firme pero un proceso flexible, adaptable en el tiempo y las formas fue clave. Una vez definido el esquema estratégico, la herramienta y escala del proyecto urbano fue la más adecuada para definir trazados, coordinar rasantes, anchuras y profundidades, diseñar el espacio público y el paisaje. El sistema de evacuación de la cuenca se transforma, moderniza y da resiliencia a la ciudad paso a paso- a través de los proyectos de transformación y regeneración que se inicia por parte de actores privados como públicos.

\section{Abstract}

Urban planning must help mitigate the effects of climate change, moderate the global rise in temperature and control the misuse of energy and hydrological resources. This research is based on a case study of the daylighting project on the river Kjørbekk in the Municipality of Skien in Norway. The project substitutes the actual storm water management in old pipes, to a visible nature-based solution (NBS), corresponding to a landscape infrastructure capable of retaining, infiltrating and transporting water and generating a new landscape of urban and territorial cohesion.

${ }^{1}$ Laboratorio de Urbanismo de la Universidad de Granada; ${ }^{2}$ Ayuntamiento de Skien, ${ }^{3}$ Escuela de Arquitectura de Oslo $(\mathrm{AHO})$ - Estudio de arquitectura y paisaje Worksonland. * Correo de contacto: celiamarmar@gmail.com 


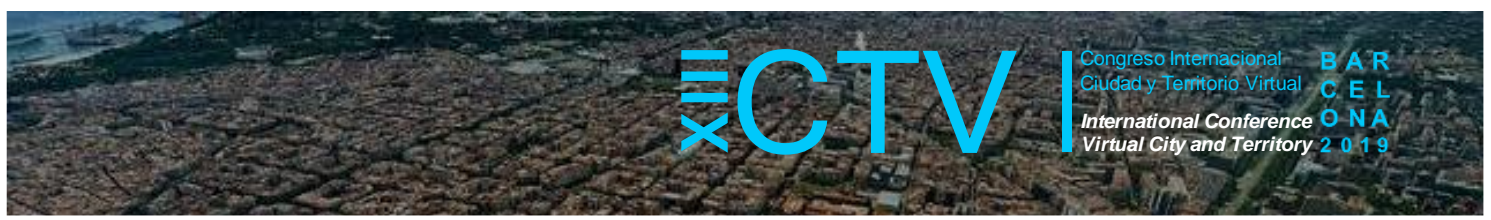

The human-made underground is a challenge for urban projects that have traditionally focused on the physical definition and legislation of what is visible, paying less attention to the invisible underground. The project reveals inherent underground constraints such as old landfills, polluted industrial ground, existing fresh and sewage water systems, fiber cables, electricity, etc. This has been necessary to map as a 'contemporary archaeology' in order to enable the design of the new waterways as well as the areas of retention and infiltration. The transformation of the old infrastructure into a new storm water management project corresponds to a system change that has demanded a design of a process over time, including both private and public actors. The urban project is under a paradigm shift which includes uncertainty and where the dynamic and the management of risk becomes a part of the project.

Palabras Clave: Agua; subsuelo; proyecto urbano; soluciones basadas en la naturaleza (SBN)

Key words: Water; subsoil; urban project; Nature-based solutions (NBS)

\section{Introducción}

\subsection{Primera fase, el encargo: "Plan estratégico de prevención de inundaciones y proyecto de rehabilitación urbano/paisajística mediante actuaciones de gestión de agua y restauración de ríos en el entorno periurbano de Kjørbekkdalen, Skien, 2015".}

Inscrito dentro de las estrategias del Ayuntamiento de Skien para la adaptación al cambio climático el plan estratégico y el anteproyecto urbano- paisajístico del Kjørbekkdalen es, a la vez, un proyecto importante para la transformación del tejido periurbano de su cuenca y la puesta en valor de este paisaje contaminado, a partir de la restauración del río y su inserción paisajística a nivel urbano cómo elemento vertebrador.

Figura 1. Plano historico del rio antes de ser entubado, con la topografía original, y trazado del nuevo curso de agua sobre el suelo urbano existente
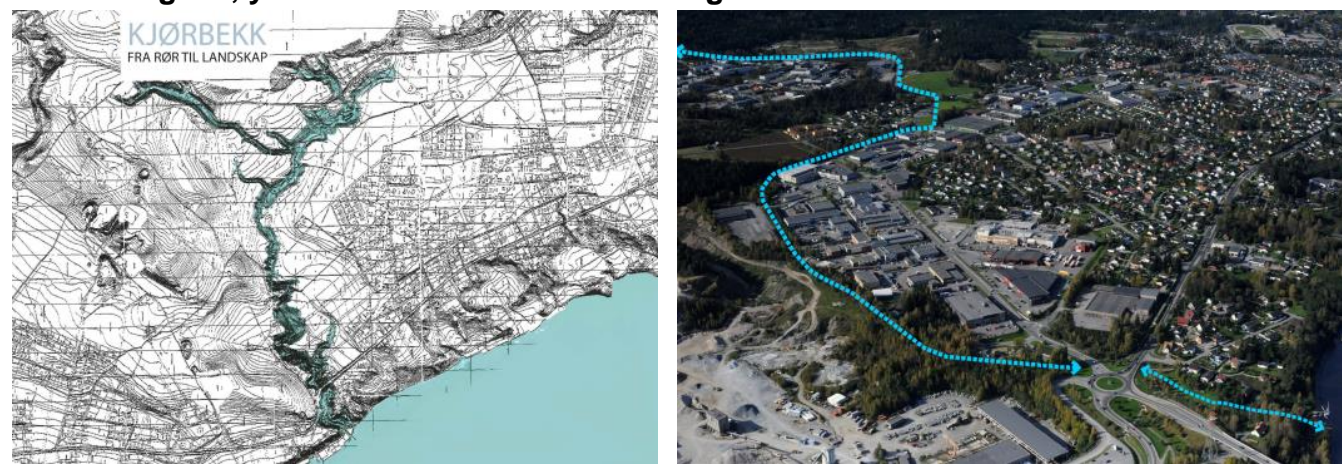

Nota: La orografía de la cuenca hidrográfica ha sido fuertemente modificada mediante desmontes y rellenos, no existiendo una red de evacuación de aguas superficiales, cuya evacuación depende de la tubería soterrada -calculada tan solo para un tercio del caudal de avenida-, en mal estado y de difícil mantenimiento por su profundidad.

Fuente: Ayuntamiento de Skien, Urbanismo y Agua.

Partiendo de la necesidad de responder al deterioro de la canalización subterránea del río y a la mejora de la red de drenaje superficial debido al incremento de las lluvias y a la posibilidad de rotura de la presa del lago, el plan-proyecto partía con los siguientes objetivos, plantear la gestión del riesgo mediante:

- un esquema de control de las avenidas de inundación en caso de rotura de la presa.

- la reapertura del río en el tejido periurbano y natural, encajando posibilidades de trazando de un nuevo cauce en planta y sección. 


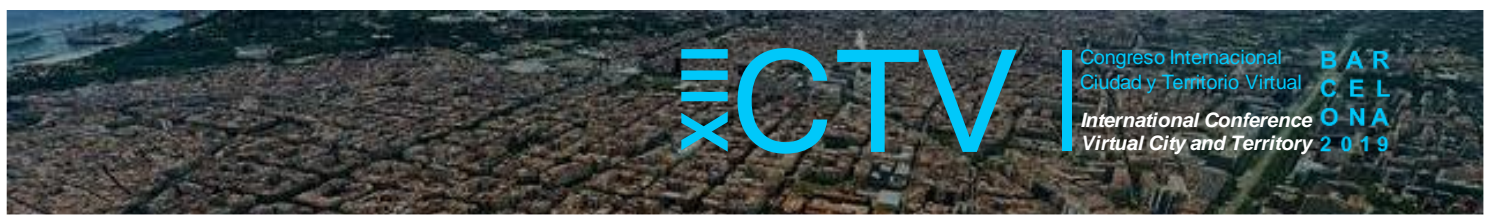

- esquema de gestión de las aguas pluviales y de las aguas contaminadas de los vertederos (en algunas áreas el relleno de basura y escombros alcanza profundidades de $15 \mathrm{~m}$ ).

- el estudio previo para el diseño del nuevo parque lineal, como elemento paisajístico e infraestructura para la gestión del agua, que se extiende desde el rio de Skien hasta la presa Hvisteintjern (aproximadamente a lo largo de $4 \mathrm{~km}$ ), creando una nueva conexión entre el río y el monte, a la vez qué aglutina en un nuevo eje verde espacios residuales.

- el anteproyecto de una red de itinerarios y lugares de ocio, a lo largo del nuevo curso del río y en relación con los senderos naturales, la estructura urbana y los equipamientos existentes.

El anteproyecto (trabajo de campo, compilacion de información, formulación y formalización de la idea) se hizo en un plazo de dos meses por parte de un equipo reducido interdisciplinar de ingeniería hidráulica, arquitectura de paisaje y urbanismo. El trabajo consistió en:

- estudio de la topografía original y la existente, mediante la realización de una veintena de secciones claves.

- estudio de los usos y la propiedad del suelo.

- compilación de los planes y proyectos existentes o futuros sobre el área.

- extracción de los datos de caudales y zonas de inundación definidas por el estudio hidrológico previo de Multiconsult, 2007.

Figura 2. Fotografías del paisaje periurbano a lo largo del nuevo eje fluvial y panorámica de la zona
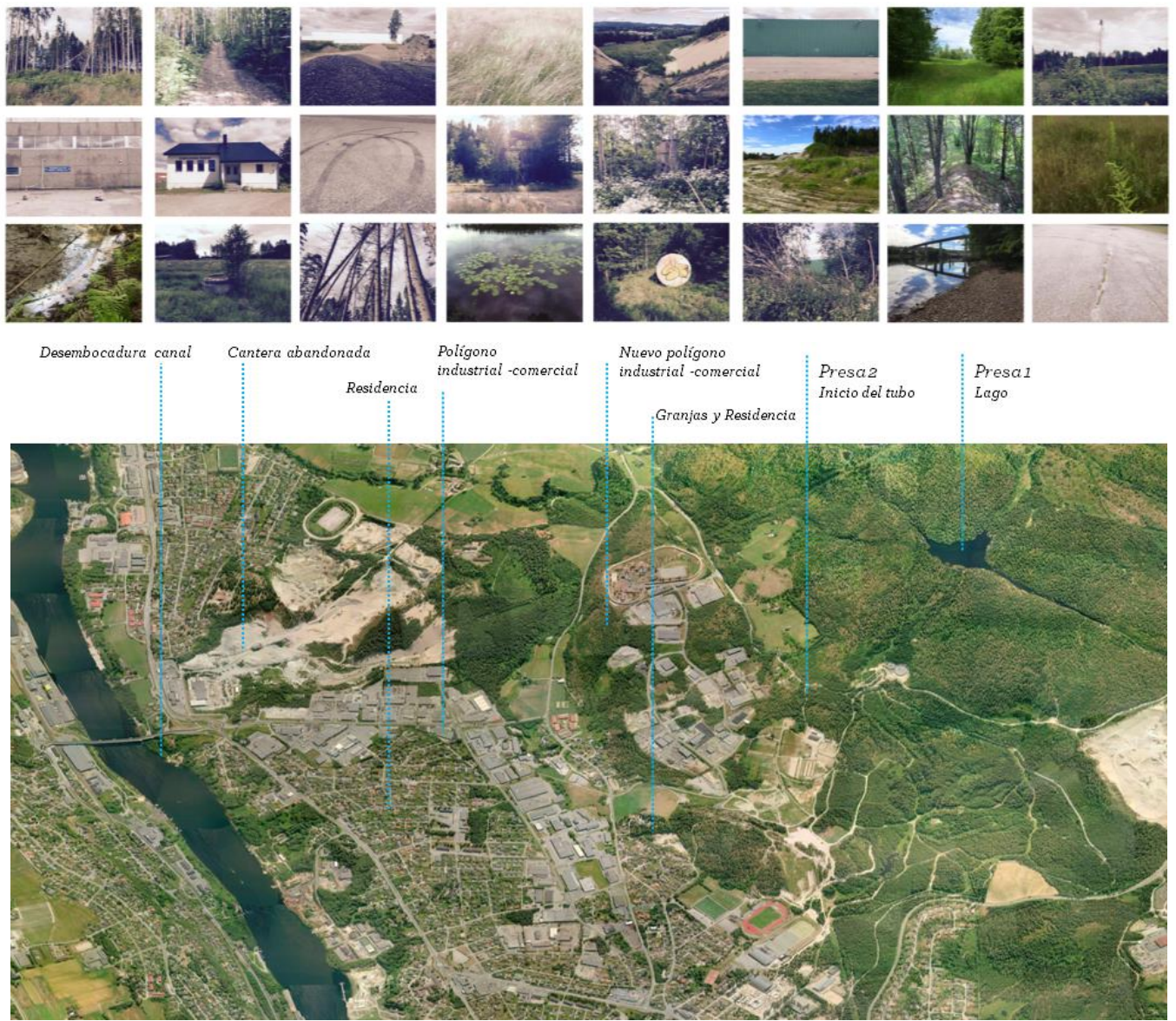

Fuente: Ayuntamiento de Skien, Urbanismo y Agua. 


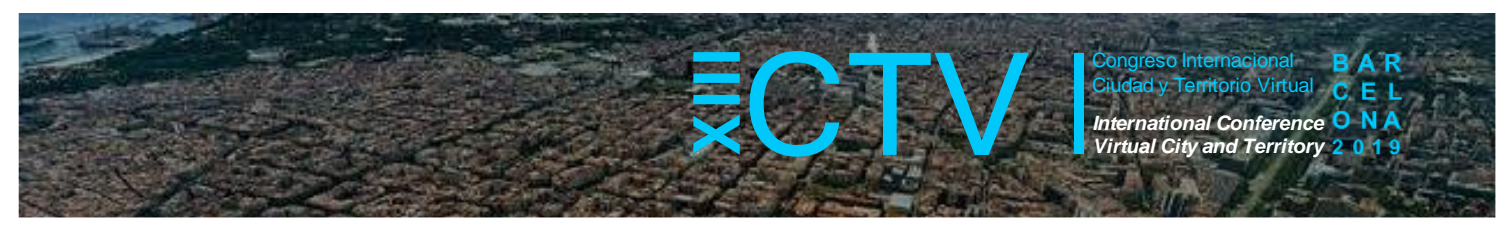

\subsection{Fase 1b-Anteproyecto: la estrategia}

Como se puede observar en la Figura 3, la estrategia consistía en:

- Disminución del volumen agua en el lago, mediante islas artificiales

- Gestión del caudal máx. (Q200) por rotura de presa en el terreno natural, comprendido entre las dos presas, mediante actuaciones de retención de agua. Para ello se propusieron ocho balsas de profundidad reducida, en función de las concavidades existentes en el terreno natural, con capacidad de acumulación aproximada $44.000 \mathrm{~m}^{3}$.

- Sustitución de la conducción subterránea del río, por un cauce natural y abierto en el tramo urbano

Figura 3. Esquema de la transformación del sistema a lo largo del tiempo- sustitución de la tubería por la nueva infraestructura verde

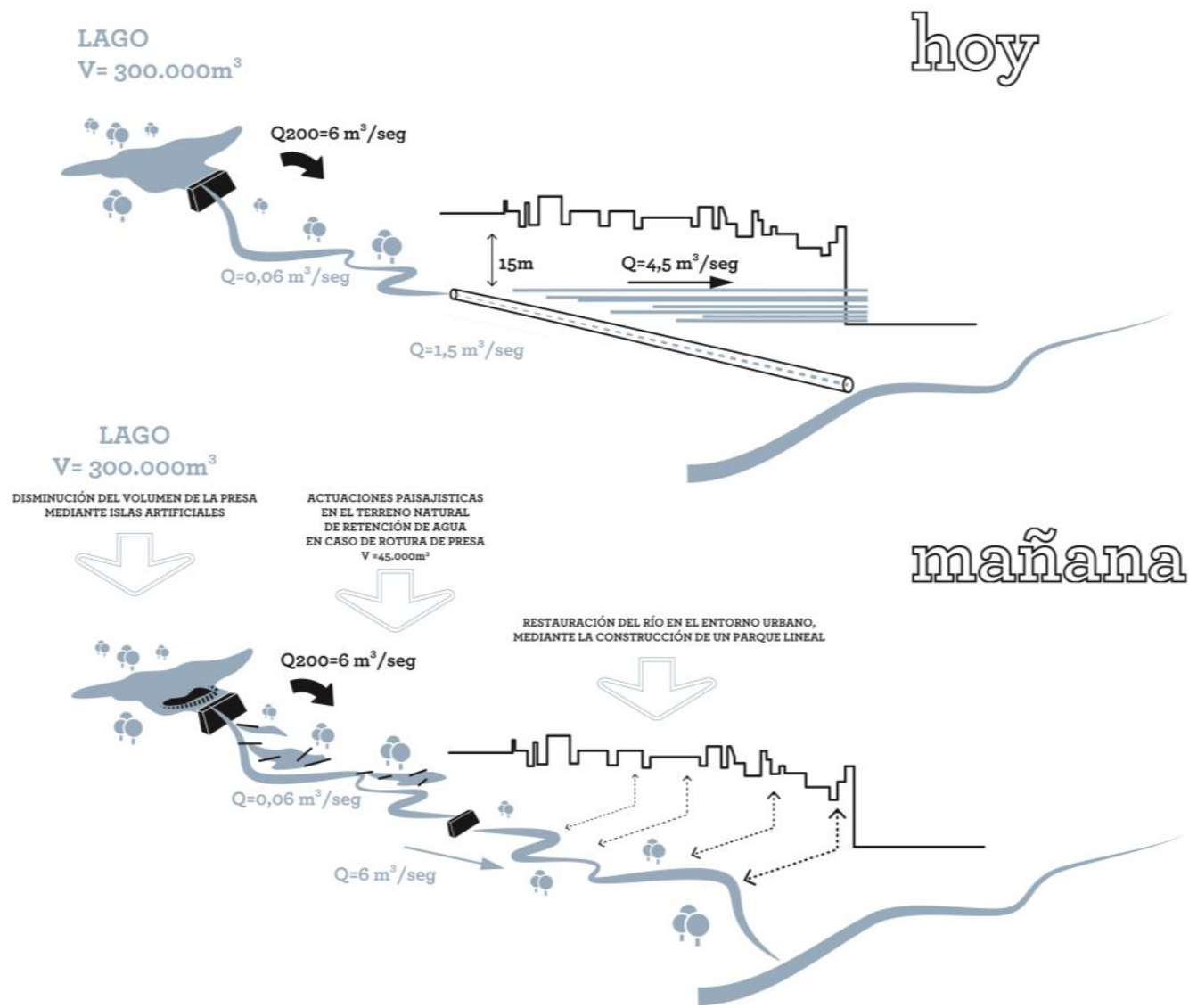

Fuente: Ayuntamiento de Skien, Urbanismo y Agua, Celia Martinez Hidalgo.

\subsection{Anteproyecto: " Kjørbekkdalen Park"}

Los parámetros de diseño del anteproyecto fueron:

A) El cauce urbano, a nivel hidráulico, se pre-diseñaba para cuatro caudales, el mínimo, el máximo, el habitual y el máximo junto con rotura de presa: $Q a=0,06 \mathrm{~m}^{3} / \mathrm{s}, \mathrm{Qb}=1 \mathrm{~m}^{3} / \mathrm{s}, \mathrm{Qc}=1,5$ $\mathrm{m}^{3} / \mathrm{s}, \mathrm{Qd}=6 \mathrm{~m}^{3} / \mathrm{s}$. 


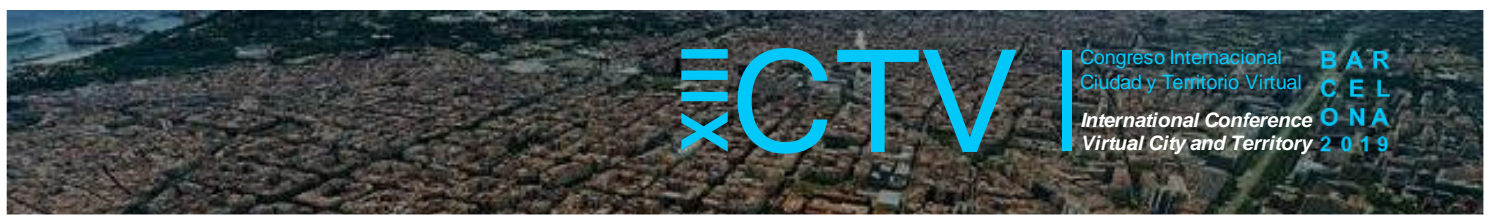

B) El cauce debía ser de tierra natural, la existente y con poco mantenimiento, lo qué definía las pendientes -tanto longitudinales como transversales- y delimitaba las velocidades para evitar erosión:

\begin{tabular}{cc}
\hline Pendiente & Vmedia(m/s) \\
\hline $\mathbf{0 - 3} \%$ & $\mathbf{0 , 3 0 4 8}$ \\
\hline $\mathbf{4 - 7} \%$ & $\mathbf{0 , 9 1 4 4}$ \\
\hline $\mathbf{8 - 1 1 \%}$ & $\mathbf{1 , 5 2 4}$ \\
& (velocidad max.< 1,52 para evitar la erosión) \\
\hline $12-15$ & $\% \quad 2,4384$ \\
\hline
\end{tabular}

C) Taludes naturales del cauce $Z=1,5: 1(\max .1: 1)$

El cauce en la media de lo posible, debía trazarse siempre dentro de los límites de propiedad pública. En aquellos lugares donde se carecía de suelo de propiedad municipal, se optó por disponer el cauce de la manera menos perjudicial para los privados, buscando los límites de la parcela y aprovechando los taludes existentes en muchas de las lindes parcelarías. Donde habia más espacio se opto por ampliar la seccion y extender el cauce para bajar las velocidades.

El cauce a lo largo de todo su recorrido irá acompañado por un itinerario urbano-paisajístico (peatonal y bicis) y de mantenimiento variable entre los 1,8-3m. Dicho camino se situó por encima del ámbito mojado por Qc. En los tramos donde ya existen senderos o ciclovías estos fueron adecuados para tan fin, incorporándolas al trazado general del recorrido. El trazado del mismo, además de los requisitos funcionales, se apoyó en el disfrute del paisaje y la búsqueda de conexión con espacios y usos urbanos del entorno (red verde, paradas de autobuses, colegios, espacios deportivos, etc.).

\section{Figura 4. Seccion que muestra un tramo y secciones sel cauce}

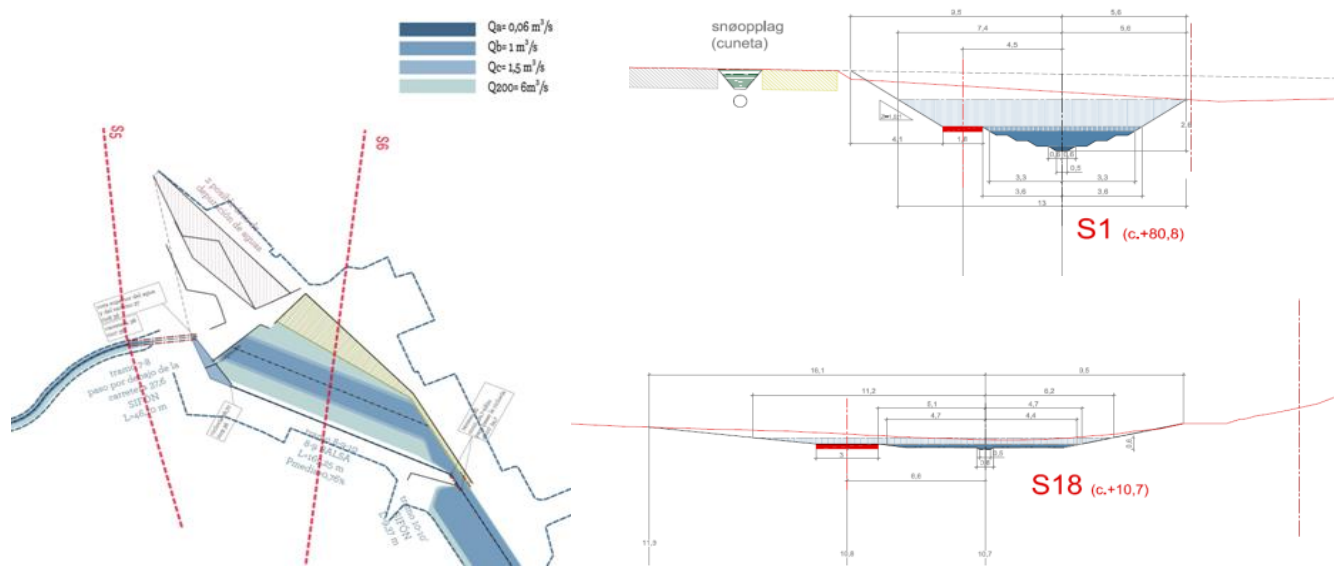

Fuente: Ayuntamiento de Skien, Urbanismo y Agua.

Las ideas reflejadas en el anteproyecto, sentaron las bases para el posterior desarrollo de las directrices urbanísticas y el proyecto técnico "Kjørbekk, fra rør til landskap" Así, cómo el trabajo realizado, se incorporó a un dossier para su divulgación pública, como documento base en el proceso de participación ciudadana, conferencias y concurrencia en programas de ayudas públicas que han ayudado a su avance. 


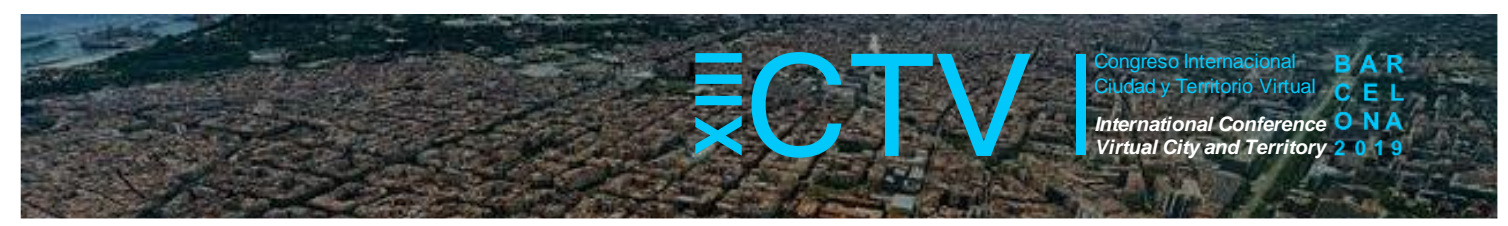

Figura 5. Nuevo corredor verde

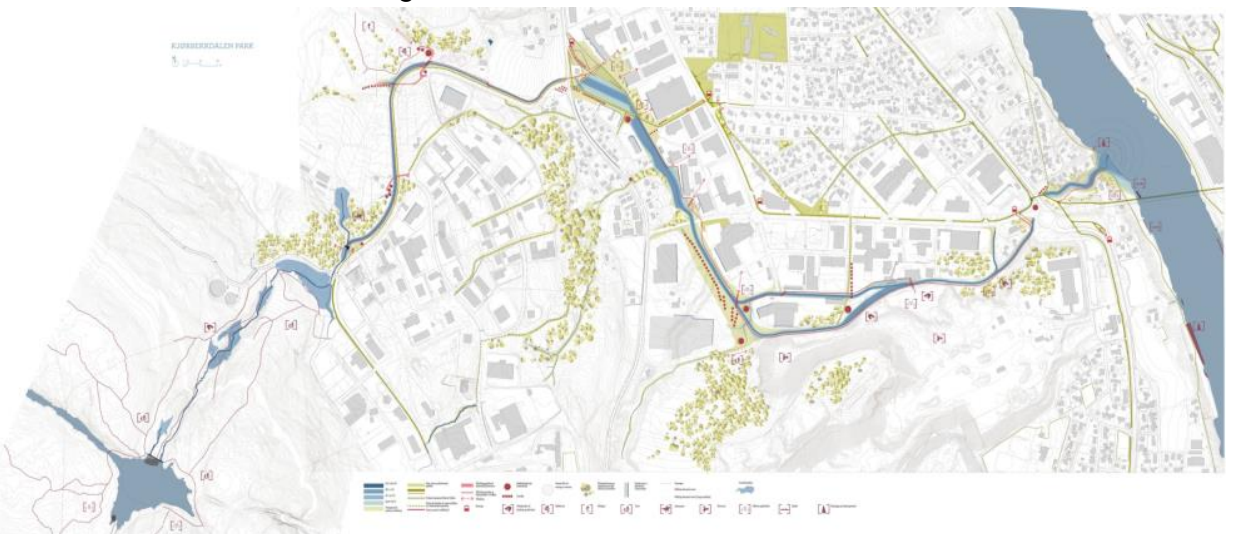

Fuente: Ayuntamiento de Skien, Urbanismo y Agua.

\section{El caso de estudio: Plan especial del parque fluvial del Kjørbekk y regulación urbanística del ámbito. Ayuntamiento de Skien, 2017-2018²}

Tras la primera fase de formulacion de la idea del proyecto se formo un equipo multidisciplinar enfocado en la interaccion de biologia, pasiaje, ingeniera, urbanismo e hidrología. La metodología del trabajo se ha basado pricipalmente en el trabajo iterativo sobre un modelo hidrológico que cohesionaba los distintos perfiles técnicos del equipo, los profesionales de las distintas disciplinas del propio ayuntamiento y las colaboraciones por parte de expertos universitarios.

\subsection{La coordinación del equipo}

La dimensión y cantidad de perfiles técnicos, hicieron necesario fijar, durante la fase de diseño, unos criterios para facilitar la coordinación interdisciplinaria. Los más importantes fueron:

- Una sección longitudinal variable, que favoreciese el movimiento y la oxigenación del agua, creando diversidad visual y biológica.

- Una sección transversal lo más amplia posible, para hacer el cauce accesible transversalmente y reducir los riesgos de erosión.

- Las oscilaciones de los volúmenes de agua a lo largo del año, hizo necesario diseñar un cauce de agua bajas en forma de $\mathrm{V}$ que pudiera mantener un nivel visible de agua en los períodos secos.

- El corredor debía discurrir por terrenos públicos y realizarse con el menor movimiento de tierras, evitando el aumento de los costes.

- Las pendientes longitudinales del cauce debían permitir que los peces remontasen el río tan arriba como fuese posible.

- La profundidad y trazado del cauce evitaría en la medida de lo posible los suelos contaminados de los vertederos.

\footnotetext{
${ }^{2}$ Encargo obtenido por concurso público de ámbito europeo por Worksonland Arkitektur Og Landskap As, Uni Research y Multiconsult, publicado en TED el día 18.10.2016 con el número de identificación 2016/S 201-364527.) El proyecto está incluido como caso piloto en del Programa Noruego de adaptación al Cambio climático «l-front» del Ministerio de Medio Ambiente (Miljodirektoratet -http://www.klimatilpasning.no. A su vez se encuentra representado por Multiconsult en la plataforma Klima 2050 - Centre for Research-based Innovation.
} 


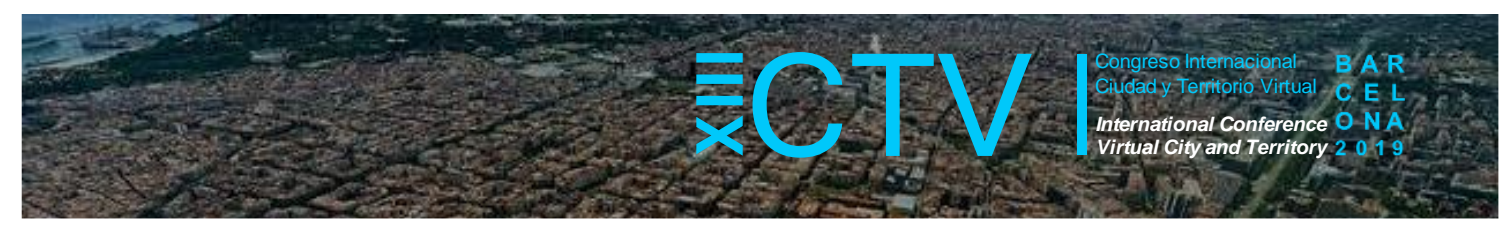

- La integración del cauce en la ciudad, adaptando su diseño a los usos, edificios adyacentes y en coordinación con los planes parciales actualmente sobre la mesa y futuros.

\subsection{El encaje urbano y la gestión del suelo: la estructura verde y los valores naturales, recreativos y urbanos.}

El corredor esta compuesto por un complejo entramado de sistemas y programas que se entrelazan y forman un único cuerpo:

- Gestiona integral de las aguas pluviales.

- Adaptación al cambio climático.

- Corredor ecológico y nuevo eje para la biodiversidad.

- Sistema público de espacios de ocio, itinerarios y senderos.

El paisaje creado por la nueva infraestructura verde, será el encargado de resolver los distintos retos planteado. La localización periférica del proyecto respecto a los lugares centrales de Skien y su condición de elemento lineal que va uniendo diversos paisajes y usos del suelo: zonas boscosas naturales, áreas agrícolas salpicadas de granjas, zonas monofuncionales terciarías con grandes parcelas dedicadas a la pequeña industria o el comercio, residencias unifamiliares y zonas educativas, ..., dotan a esta infraestructura verde y de control de las inundaciones de un valor añadido, la posibilidad de llegar a ser un "lugar", el parque del Flomveg Kjørbekk. El canal de inundación, en su recorrido, aparece flanqueado por un camino de al menos $3 \mathrm{~m}$ de ancho que permite recorrer de manera continua los aproximadamente $5 \mathrm{~km}$ existentes entre el lago y la desembocadura.

El diseño busca favorecer la construcción de esta infraestructura social, este nuevo o reconstruido paisaje fluvial, a lo largo del tiempo y con la suficiente flexibilidad para incorporar las necesidades y deseos de los ciudadanos. Por ello, se trata de construir un soporte, una base sobre la que poco a poco tanto la naturaleza como la ciudad puedan ir sumando y añadiendo, por ejemplo: conexiones transversales (véase la propuesta para toda la cuenca de sistemas de recogida de agua mediante corredores verdes), espacios de ocio y/o deportivos vinculados a los usos educativos adyacentes, zonas para comer los trabajadores de los usos terciarios, espacios de juego, etc.

Se ha diseñado con el fin de activar y entrar en interacción con el tejido y programa urbano contiguo; como son los usos terciarios y educativos, las distintas densidades residenciales, las paradas de transporte público existentes, y/o los puentes y lugares de conexión con otras rutas o ciclovías existentes o proyectadas. Así algunas zonas, se perfilan como centrales a lo largo del parque lineal: la zona de la desembocadura convertida en un delta artificial en conexión con los recorridos públicos que en un futuro recorrerán el Skienselva y que lo comunicarán con el centro de la ciudad, las pista deportivas o lugares de recreo del colegio público Skogmo ampliadas y puestas en relación con el paisaje-, la zona de parque urbano junto al tejido industrial y comercial, etc.

\subsection{La hidráulica y la gestión del riesgo}

La cueca que drena al rio Skienselva cubre un área total de $3,11 \mathrm{~km}^{2}$. Comienza en la presa Hvitsteintjern, que fue reserva de agua potable y que hoy es un área recreativa para la ciudad. La cuenca que drena a la presa es de un tamaño reducido, lo que significa que el rio algunos 


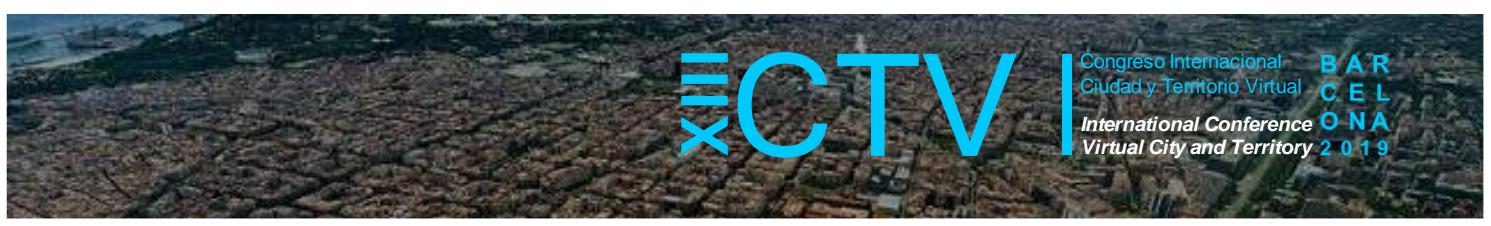

días al año no pueda asegurar un caudal mínimo (ver Figura 7), sus coberturas y usos son variables: suelo urbano, de bosque y de agricultura. La parte alta es mas boscosa y permeable, mientras que la parte baja aparece impermeabilizada por la urbanización, lo que la hace más vulnerable a las inundaciones.

Figura 6. Isométrica de la cuenca fluvial del Kjørbekkdalen. Superficie: $\mathbf{3 , 1 1 ~ k m 2 ~}$

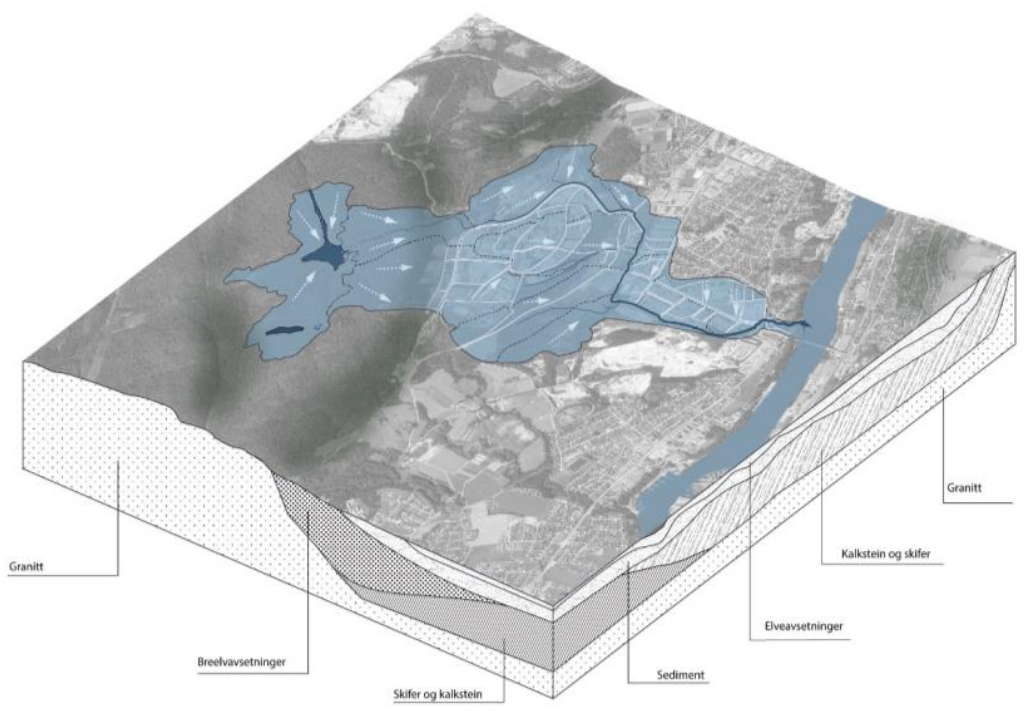

Fuente: Worksonland, 2018.

Figura 7. La gráfica muestra la variabilidad de caudales del Kjørbekkdalen (I/s), la a lo largo del año, y el mapa las zonas inundables por la rotura de presa
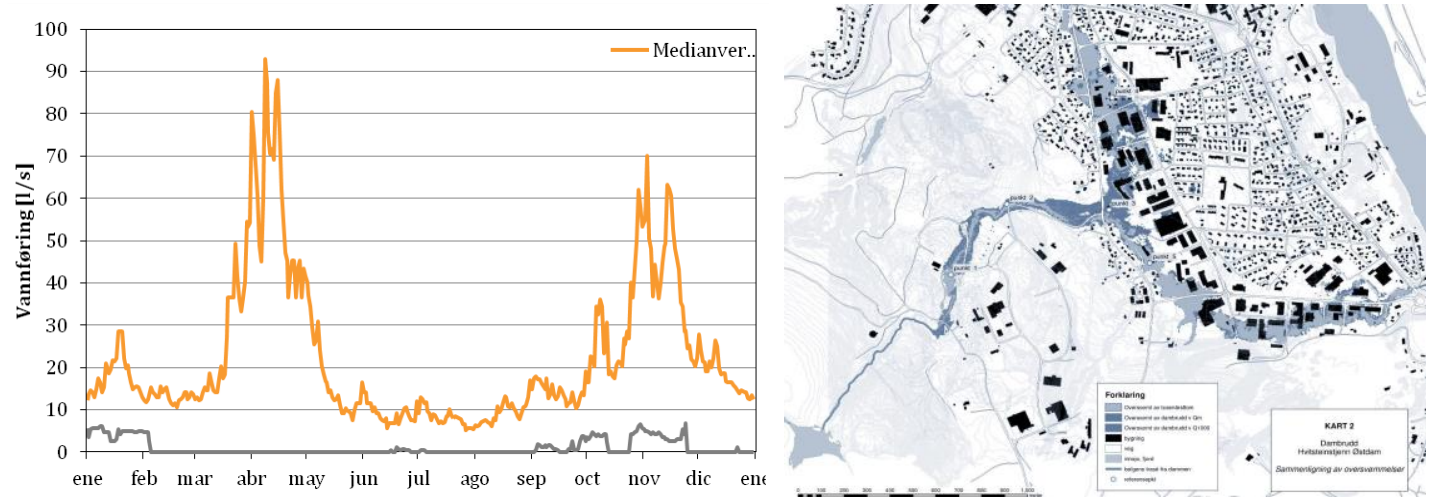

Fuente: Multiconsult, 2017.

El modelo hidráulico realizado por Multiconsult en 2007, muestra las consecuencias de la rotura de presa del lago Hvitsetintjern y los daños materiales que producirían en el tejido urbano. El modelado del paisaje se ha hecho por tanto con el objetico de evitar este riesgo, implementando estudios y medidas como reducir el volumen del lago, fortalecer la presa, reducir la velocidad del agua, etc., con el fin de aumentar la capacidad del paisaje para gestionar, almacenar y dirigir el agua hacia donde menos daños produzca. La gestión de los conflictos existentes entre la edificación, las infraestructuras y el agua se ha resuelto mediante: 1 el diseño del nuevo cauce, 2 el modelando del terreno, 3 la regulación y el diseño de los grados de permeabilidad del suelo. 


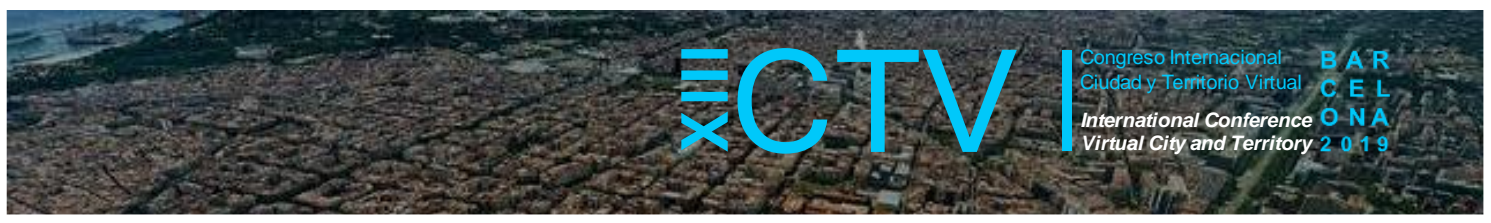

Figura 8. Sub-cuencas hidrográficas y precipitaciones asociadas
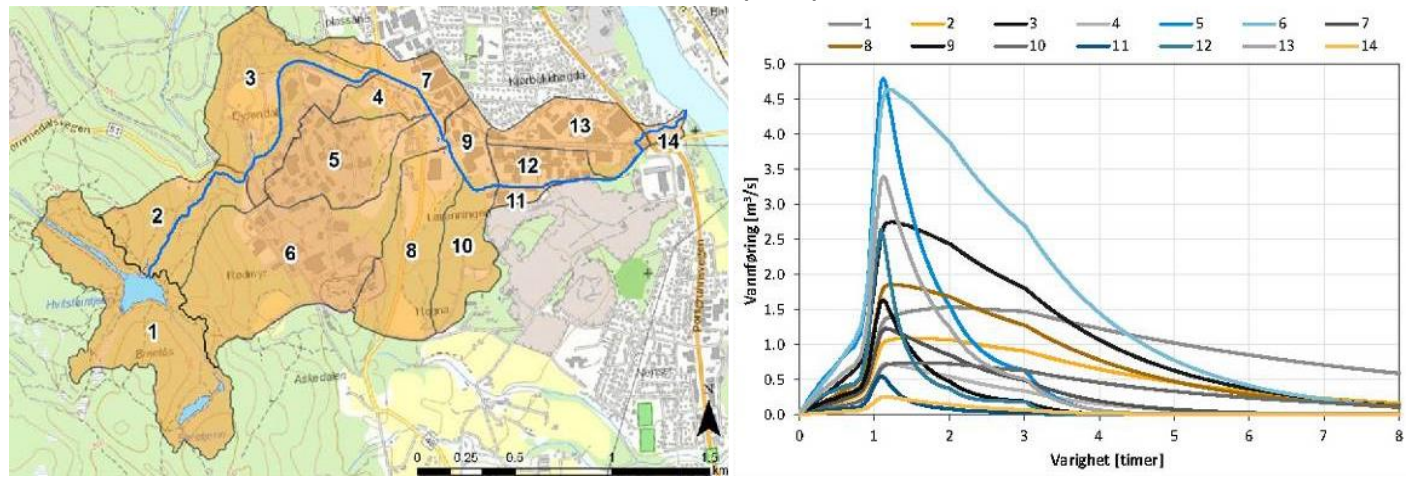

Fuente: Multiconsult, 2017.

El gráfico a la derecha muestra el caudal en $\mathrm{m} 3 / \mathrm{s}$ para cada subcuenca. Sobre las subcuencas que aportan más agua al nuevo cauce, se han propuesto medidas para reducir, ralentizar y disminuir los volúmenes de agua. Se ha trabajado principalmente en la reducción de los picos del hirdograma y del coeficiente de escorrentía, proponiendo una gestión en superficie de las pluviales en el ámbito urbanizado.

Figura 9. Estudio de las coberturas del suelo

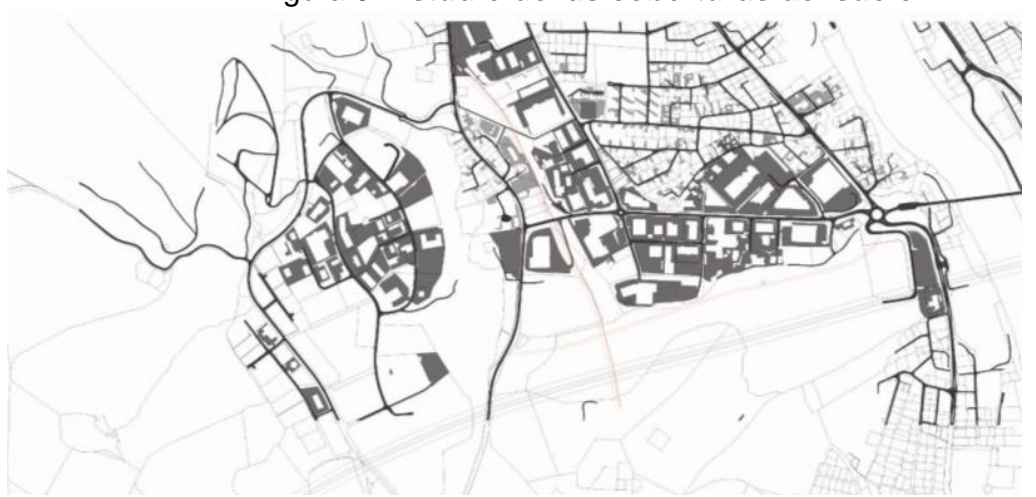

Nota: en gris las superficies impermeables, en negro carreteras y calles.

Fuente: Celia Martínez Hidalgo, 2018.

Figura 10. Estudio de las coberturas del suelo

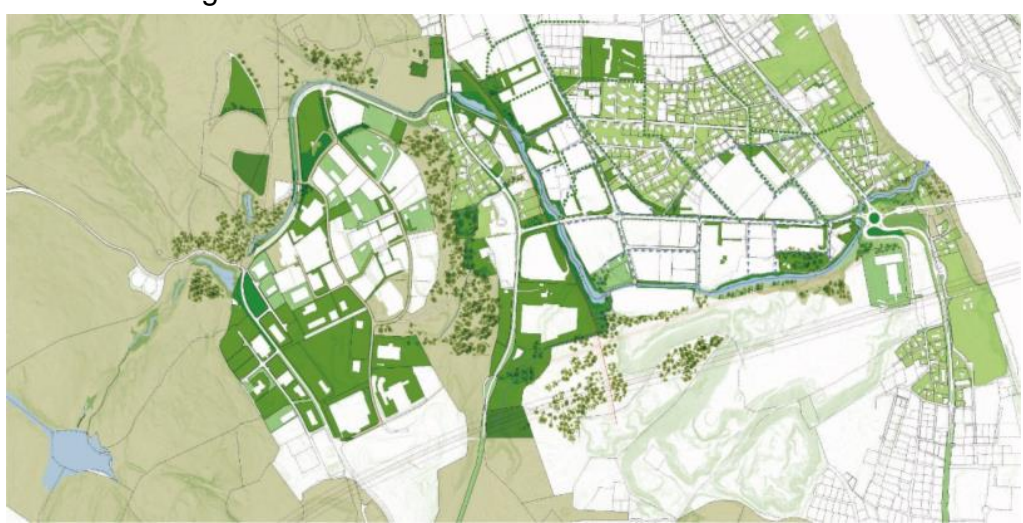

Nota: el plano muestra las distintas superficies permeables de la cuenca (en verde claro las parcelas de uso residencial, en verde oscuro las grandes parcelas industriales, en verde seco las zonas boscosas).

Fuente: Celia Martínez Hidalgo, 2018. 


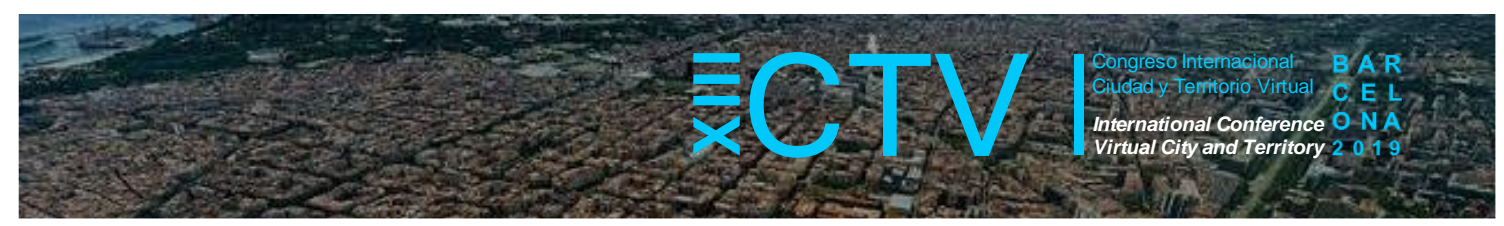

El análisis de los distintos tipos de suelo y usos ha permitido implementar en la ordenanza algunas medidas sobre el suelo privado que favorezcan el control de inundaciones. Puede observarse como las parcelas industriales de grandes dimensiones impermeabilizan una gran cantidad de terreno, en ellas podrían incentivarse operaciones de adecuación ambiental del paisaje urbano que mejorasen la calidad urbana y favoreciesen la retención de agua, por ejemplo:

- Incorporación de zonas ajardinadas.

- Picado o sustitución de un \% del suelo por pavimento permeables.

- Linderos verdes contiguos entre parcelas.

- Actuaciones en las cubiertas, techos verdes.

Por otra parte, las parcelas residenciales cuentan de medía con una parcela de menores dimensiones y débilmente urbanizadas. En muchos casos las parcelas definen sus linderos con un terraplén de tierra natural, parece razonable pensar que, aunque sea terreno privado pueden acometerse operaciones de canales abiertos para recoger el agua de las parcelas y viarios de acceso en estas franjas de terreno. La gran superficie ajardinada con la que cuentan la mayoría de parcelas permite fomentar la implementación de zonas de acumulación/depuración de agua dentro de las mismas.

\subsection{El plan de la cuenca y el corredor}

La Directiva 2007/60/EC de la Unión Europea define inundación como el cubrimiento temporal por agua de una tierra que normalmente no se encuentra cubierta [...] Para el estudio de este fenómeno, probabilidad de aparición, cuantificación de sus consecuencias..., se establece el concepto de riesgo. Éste se define como la combinación de una probabilidad de presentación de un determinado evento, llamado peligro, y las potenciales consecuencias adversas que tendría este evento para la salud humana, el medio ambiente, el patrimonio cultural o las actividades económicas, que se denominan vulnerabilidad. De manera, que el riesgo se define como el producto del peligro y la vulnerabilidad, asociadas en este caso, a una inundación. EI análisis del riesgo de inundación consiste en determinar la naturaleza y extensión del riesgo existente mediante el análisis de las amenazas potenciales y evaluación de las condiciones de vulnerabilidad que pueden derivarse de la amenaza potencial, causando daños personales, a la propiedad y al medio ambiente. Las medidas para reducir el riesgo de inundación se dividen en dos grupos: medidas estructurales y medidas no estructurales.

El "Kjørbekk- fra rør til landskap. Prosjektering og regulering av flomveg og tilhørende grønnstruktur, Skien Kommune" ha de entenderse cómo una infraestructura capaz de reducir el riesgo implementando medidas estructurales. El entendimiento conjunto de la cuenca drenante otorga al proyecto la capacidad de simular el drenaje natural del lugar previo desarrollo urbanístico y la modificación del terreno mediante rellenos según tres medidas estructurales:

1 Nuevo encauzamiento.

2 Implementación progresiva de un sistema de drenaje sostenible (SuDS).

3 Criterios urbanísticos ad-hoc (ordenanza).

Algunas estrategias posibles que pueden adoptarse para reducir el riesgo de inundación y mitigación de los efectos del cambio climático, con el objetivo de minimizar los impactos de la escorrentía y maximizar las oportunidades de servicio y biodiversidad, pueden ser las que se muestran en la tabla 1. 


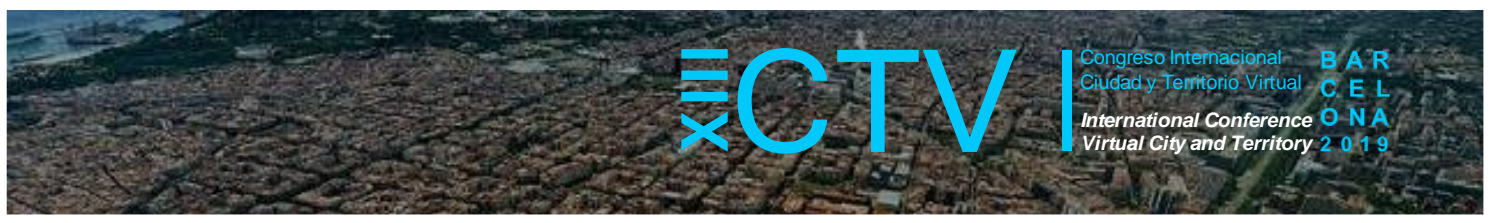

Tabla 1. Estrategias posibles que pueden adoptarse para reducir el riesgo de inundación y mitigación de los efectos del cambio climático

Optimización de la vegetación urbana. Aumentando las áreas arboladas, el arbolado de alineación y favoreciendo su conexión

\footnotetext{
Optimización de la estructura viaria y los espacios de estacionamiento: reduciendo al mínimo la superficie de tránsito pavimentada e incorporando coberturas permeables
}

Regular el uso de suelo en áreas urbanizables

Promover, mediante mecanismos que alienten y viabilicen iniciativas de autogestión de las pluviales dentro de las parcelas privadas

Promover mecanismos que favorezcan la remodelación de los suelo existentes y su densificación frente a la extensión de nuevos suelos artificiales

Sin embargo, aunque el plan/proyecto nazca de la necesidad de dar una respuesta técnica al problema de gestión de aguas superficiales del área, sus beneficios desbordan el ámbito de la salubridad, pudiendo señalarse los indicados en la tabla 2.

Tabla 2. Beneficios

\begin{tabular}{llll} 
& Sociales & Económicos & Ambientales \\
\hline $\begin{array}{l}\text { La recualificación urbana de todos los sectores que se } \\
\text { ubican a lo largo de los cursos de agua. }\end{array}$ & $\mathrm{X}$ & $\mathrm{X}$ & \\
\hline La configuración de enclaves singulares & $\mathrm{X}$ & $\mathrm{X}$ & $\mathrm{X}$ \\
\hline El saneamiento de los cursos de agua & $\mathrm{X}$ & $\mathrm{X}$ & $\mathrm{X}$ \\
\hline $\begin{array}{l}\text { La gestión de reservas de suelo para futuras } \\
\text { transformaciones urbanas }\end{array}$ & $\mathrm{X}$ & $\mathrm{X}$ & \\
\hline $\begin{array}{l}\text { La conformación de un sistema de parques } \\
\text { metropolitanos }\end{array}$ & & $\mathrm{X}$ \\
\hline $\begin{array}{l}\text { La definición de un sistema de movilidad saludable } \\
\text { paralelo a los cursos de agua }\end{array}$ & $\mathrm{X}$ & $\mathrm{X}$ & $\mathrm{X}$ \\
\hline $\begin{array}{l}\text { La concertación con los propietarios del suelo para el } \\
\text { desarrollo de las urbanizaciones planificadas y } \\
\text { programadas }\end{array}$ & & $\mathrm{X}$ & $\mathrm{X}$ \\
\hline $\begin{array}{l}\text { Proteger los sistemas naturales y mejorar el ciclo del } \\
\text { agua en el entorno urbano }\end{array}$ & & $\mathrm{X}$ & $\mathrm{X}$ \\
\hline $\begin{array}{l}\text { Reducir los caudales punta disminuyendo el riesgo de } \\
\text { inundación aguas abajo }\end{array}$ & $\mathrm{X}$ & \\
\hline $\begin{array}{l}\text { Restituir el flujo subterráneo hacia los cursos naturales } \\
\text { mediante infiltración }\end{array}$ & & & \\
\hline
\end{tabular}

Dentro de cada una de las medidas estructurales puede dictarse o fomentarse acciones y estrategias según los elementos urbanos y los usos del suelo:

\subsubsection{Nuevo encauzamiento}

Apertura del cauce fluvial y definición del área inundable

- Definición de los usos del suelo según las llanuras de inundación:

- Z.I. para lluvias habituales (1año): el suelo será clasificado como zona inundable I y estructura prioritaria del sistema general de espacios verdes urbanos y de la matriz medioambiental.

- Z.I. para lluvias esporádicas (5-10años): el suelo será clasificado como zona inundable Il y estructura prioritaria del sistema de espacios verdes urbanos. Pudiendo albergar elementos de la red de caminos peatonales - ciclovías y áreas de actividad vinculadas 


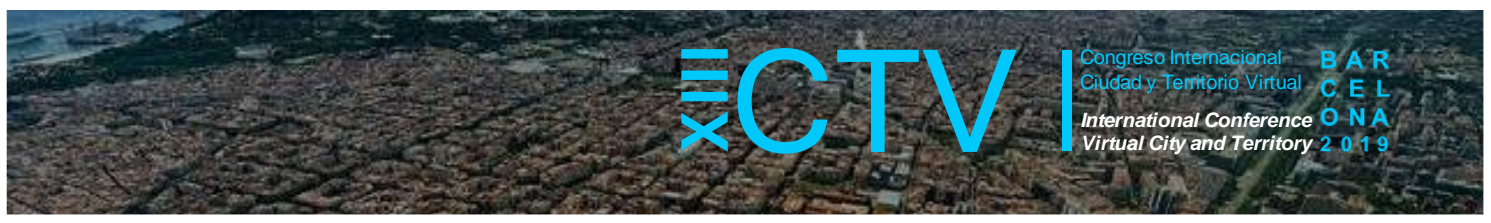

al esparcimiento y el deporte que no supongan una barrera o obstáculo al drenaje del área (lugares de reunión, pistas deportivas, etc).

- Z.I. para lluvias excepcionales (200 años): el suelo será clasificado como zona inundable III y estructura secundaría del sistema de espacios verdes urbanos. Pudiendo albergar elementos de la red de caminos peatonales - ciclovías y áreas de actividad vinculadas al esparcimiento y el deporte que no supongan una barrera 0 obstáculo al drenaje del área (lugares de reunión, pistas deportivas, etc).

\subsubsection{Implementación progresiva de un sistema de drenaje sostenible (SuDS)}

Las estructuras SuDS más comunes que pueden implementarse según los elementos urbanos del ámbito son: los que se muestran en la tabla siguiente.

Tabla 3. Estructuras SuDS que pueden implementarse en el ámbito

\begin{tabular}{|c|c|c|c|c|}
\hline USO & SUDS & DESCRIPCIÓN Y BENEFICIOS & CARACTERISTICAS FISICAS & OBJETIVOS \\
\hline \multirow[t]{4}{*}{ Edificación } & $\begin{array}{l}01 \text { Cubiertas } \\
\text { Vegetadas }\end{array}$ & $\begin{array}{l}\text {-Sistemas multicapa instalados en los } \\
\text { techos de las edificaciones, diseñados } \\
\text { para retener el agua de lluvia, mejorar } \\
\text { su calidad y permitir su reutilización en } \\
\text { usos no consuntivos. Pueden ser } \\
\text { intensivas (con vegetación de gran } \\
\text { porte) o extensivas (de menor porte). } \\
\text { - Mejoran el paisaje, disminuyendo la } \\
\text { temperatura del edificio e implican al } \\
\text { usuario en la gestión del agua. }\end{array}$ & $\begin{array}{l}\text { Intensivas: } \\
\text { Capacidad de } \\
\text { almacenamiento: media del } \\
45 \% \text { de su volumen } \\
\text { Extensivas: capacidad de } \\
\text { almacenamiento: media del } \\
20 \% \text { de su volumen }\end{array}$ & $\begin{array}{l}\text { Retención } \\
\text { Depuración } \\
\text { Reutilización }\end{array}$ \\
\hline & $\begin{array}{l}02 \text { Depósitos } \\
\text { Domésticos }\end{array}$ & $\begin{array}{l}\text {-Depósitos de agua adosados a los } \\
\text { edificios y conectados a sus cubiertas, } \\
\text { que almacenan el agua de lluvia } \\
\text { procedente de ellas permitiendo su } \\
\text { reutilización en usos no consuntivos. } \\
\text {-Aumentan los recursos hídricos } \\
\text { disponibles e implican al usuario en la } \\
\text { gestión del agua. }\end{array}$ & $\begin{array}{l}\text { Superficiales o subterráneos: } \\
\text { calculo en función del V }\end{array}$ & $\begin{array}{l}\text { Retención } \\
\text { Reutilización }\end{array}$ \\
\hline & $\begin{array}{l}03 \text { Pozos de } \\
\text { Infiltración }\end{array}$ & $\begin{array}{l}\text {-Estructuras verticales generalmente } \\
\text { subterráneas que infiltran el agua de } \\
\text { escorrentía procedente de superficies } \\
\text { impermeables (pavimentos, } \\
\text { cubiertas...). } \\
\text {-Disminuyen la temperatura del suelo y } \\
\text { el riesgo de inundación. }\end{array}$ & $\begin{array}{l}\text { Profundidad: } 1 \text { a } 3 \mathrm{~m} \\
\text { Diámetro: } 1 \text { a } 2 \mathrm{~m} \\
\text { Superficie recogida<0, } 5 \text { ha }\end{array}$ & Infiltración \\
\hline & $\begin{array}{l}04 \text { Zanjas de } \\
\text { Infiltración }\end{array}$ & $\begin{array}{l}\text {-Estructuras longitudinales } \\
\text { generalmente rellenas con material } \\
\text { granular, que infiltran el agua de } \\
\text { escorrentía procedente de superficies } \\
\text { impermeables (pavimentos, } \\
\text { cubiertas...), transportándola a lugares } \\
\text { para su infiltración. } \\
\text {-Disminuyen la temperatura del suelo y } \\
\text { el riesgo de inundación. }\end{array}$ & $\begin{array}{l}\text { Profundidad: } 1 \text { a } 2 \mathrm{~m} \\
\text { Anchura: } 0,5 \text { a } 1 \mathrm{~m} \\
\text { Pendiente: } 2 \text { a } 5 \% \\
\text { Superficie recogida<2 ha }\end{array}$ & Infiltración \\
\hline \multirow[t]{2}{*}{ Acera } & $\begin{array}{l}\text { 05 Pavimentos } \\
\text { adoquinados } \\
\text { o modulares }\end{array}$ & $\begin{array}{l}\text {-Superficies que retienen e infiltran el } \\
\text { agua de escorrentía a través del } \\
\text { espacio existente entre piezas. } \\
\text {-Disminuyen la temperatura del suelo y } \\
\text { el riesgo de inundación. }\end{array}$ & $\begin{array}{l}\text { Espesor: } 40 \text { a según tipo } \mathrm{cm} \\
\text { Pendiente: } 2 \text { a } 5 \% \\
\text { Superficie recogida }<4 \text { ha }\end{array}$ & $\begin{array}{l}\text { Retención } \\
\text { Infiltración }\end{array}$ \\
\hline & $\begin{array}{l}06 \text { Jardines } \\
\text { de lluvia }\end{array}$ & $\begin{array}{l}\text {-Elementos vegetados insertados en las } \\
\text { aceras que retienen, tratan e infiltran el }\end{array}$ & $\begin{array}{l}\text { Anchura }>1,5 \mathrm{~m} \\
\text { Profundidad: } 1,3 \mathrm{~m}\end{array}$ & $\begin{array}{l}\text { Retención } \\
\text { Infiltración }\end{array}$ \\
\hline
\end{tabular}




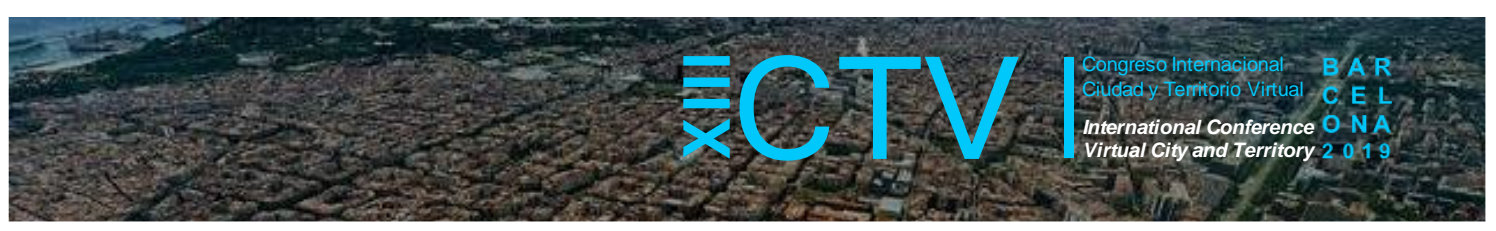

\begin{tabular}{|c|c|c|c|c|}
\hline & & $\begin{array}{l}\text { agua de escorrentía procedente de la } \\
\text { calzada. } \\
\text {-Regeneran el paisaje, disminuyen la } \\
\text { temperatura del suelo y el riesgo de } \\
\text { inundación. }\end{array}$ & $\begin{array}{l}\text { Relación: ancho / profundo: } \\
2 / 1 \\
\text { Superficie de recogida un 90- } \\
95 \% \text { más de la propia }\end{array}$ & Depuración \\
\hline & $\begin{array}{l}07 \text { Pavimentos } \\
\text { Continuos }\end{array}$ & $\begin{array}{l}\text {-Superficies que retienen e infiltran el } \\
\text { agua de escorrentía a través de sus } \\
\text { poros. } \\
\text {-Disminuyen la temperatura del suelo y } \\
\text { el riesgo de inundación. }\end{array}$ & $\begin{array}{l}\text { Espesor: } 25 \text { a30 cm } \\
\text { Pendiente: } 2 \text { a } 5 \% \\
\text { Superficie recogida<4ha }\end{array}$ & $\begin{array}{l}\text { Retención } \\
\text { Infiltración }\end{array}$ \\
\hline Calzada & $\begin{array}{l}08 \text { Drenes } \\
\text { Filtrantes }\end{array}$ & $\begin{array}{l}\text {-Zanjas de material granular (pueden } \\
\text { estar recubiertas por geotextiles), que } \\
\text { depuran e enlitran el agua de } \\
\text { escorrentía procedente de zonas } \\
\text { impermeables. } \\
\text {-Aumentan los recursos subterráneos y } \\
\text { disminuyen el riesgo de inundación }\end{array}$ & $\begin{array}{l}\text { Profundidad: } 0,7 \text { a } 0,8 \mathrm{~m} \\
\text { Anchura: } 0,45 \text { a } 0,8 \mathrm{~m} \\
\text { Pendiente: } 2 \text { a } 5 \% \\
\text { Superficie recogida }>2 \text { ha }\end{array}$ & $\begin{array}{l}\text { Infiltración } \\
\text { Depuración }\end{array}$ \\
\hline \multirow[t]{2}{*}{ Estacionamiento } & $\begin{array}{l}09 \text { Pavimentos de } \\
\text { geoceldas }\end{array}$ & $\begin{array}{l}\text {-Superficies que retienen e infiltran el } \\
\text { agua de escorrentía a través del } \\
\text { espacio existente entre piezas. } \\
\text { (disminución del volumen de } \\
\text { escorrentía hasta en un } 60 \% \text { ) } \\
\text {-Disminuyen la temperatura del suelo y } \\
\text { el riesgo de inundación. }\end{array}$ & $\begin{array}{l}\text { Espesor: } 30 \text { a } 60 \mathrm{~cm} \\
\text { Pendiente: } 2 \text { a } 5 \% \\
\text { Superficie recogida<4ha }\end{array}$ & $\begin{array}{l}\text { Retención } \\
\text { Infiltración }\end{array}$ \\
\hline & $\begin{array}{l}10 \text { Zanjas } \\
\text { filtrantes }\end{array}$ & $\begin{array}{l}\text {-Suelos de granulometría mixta con } \\
\text { vegetación que retienen e infiltran el } \\
\text { agua de escorrentía procedente de } \\
\text { superficies impermeables. } \\
\text {-Aumentan los recursos subterráneos y } \\
\text { disminuyen el riesgo de inundación. }\end{array}$ & $\begin{array}{l}\text { Profundidad }<50 \mathrm{~cm} \\
\text { Anchura }>6 \mathrm{~m} \text { Pendiente: } 2 \mathrm{a} \\
6 \% \\
\text { Longitud max.: } 50 \mathrm{~m}\end{array}$ & $\begin{array}{l}\text { Retención } \\
\text { Infiltración }\end{array}$ \\
\hline \multirow[t]{4}{*}{ Espacio libre } & $\begin{array}{l}11 \text { Cunetas } \\
\text { verdes }\end{array}$ & $\begin{array}{l}\text {-Canales vegetados anchos y poco } \\
\text { profundos que infiltran y transportan el } \\
\text { agua de escorrentía hasta las zonas de } \\
\text { infiltración. } \\
\text {-Regeneran el paisaje, aumentan los } \\
\text { recursos subterráneos y disminuyen el } \\
\text { riesgo de inundación. }\end{array}$ & $\begin{array}{l}\text { Profundidad }<55 \text { a } 7 \mathrm{~cm} \\
\text { Anchura }>0,5 \mathrm{~m}(2 \text { a } 3 \mathrm{~m}) \\
\text { Talud: } 25 \text { a } 35 \% \\
\text { Pendiente: } 2 \text { a } 4 \% \\
\text { Longitud min.: } 30 \mathrm{~m} \\
\text { Superficie recogida }<2 \text { ha }\end{array}$ & $\begin{array}{l}\text { Retención } \\
\text { Infiltración }\end{array}$ \\
\hline & $\begin{array}{l}12 \text { Estanques de } \\
\text { retención }\end{array}$ & $\begin{array}{l}\text {-Embalses superficiales que retienen, } \\
\text { infiltran y depuran el agua de } \\
\text { escorrentía procedente de otras zonas. } \\
\text {-Regeneran el paisaje, aumentan los } \\
\text { recursos subterráneos y disminuyen el } \\
\text { riesgo de inundación }\end{array}$ & $\begin{array}{l}\text { Anchura: } 3 \text { a } 5 \mathrm{~m} \\
\text { Relación longitud y el ancho } \\
\text { del estanque: } 3 / 1 . \\
\text { Profundidad: } 1,2 \text { a } 2 \mathrm{~m} \\
\text { Talud: } 25 \text { a } 35 \% \\
\text { Superficie recogida>30 ha } \\
\text { Pendiente< } 15 \%\end{array}$ & $\begin{array}{l}\text { Retención } \\
\text { Infiltración } \\
\text { Depuración }\end{array}$ \\
\hline & 13 Humedales & $\begin{array}{l}\text {-Estanques superficiales con una } \\
\text { reserva permanente de agua que } \\
\text { retienen, infiltran y depuran el agua de } \\
\text { escorrentía procedente de otras zonas. } \\
\text {-Regeneran el paisaje, aumentan los } \\
\text { recursos subterráneos y mejoran la } \\
\text { calidad del agua. }\end{array}$ & $\begin{array}{l}\text { Anchura }>5 \mathrm{~m} \\
\text { Relación } \\
\text { Profundidad: variable max. } 5 \mathrm{~m} \\
\text { (diferencia de cota } 0,9 \text { a } 1 \text {, } \\
5 \mathrm{~m} \text { ) } \\
\text { Superficie aprox. } 10 \text { ha }\end{array}$ & $\begin{array}{l}\text { Retención } \\
\text { Infiltración } \\
\text { Depuración }\end{array}$ \\
\hline & $\begin{array}{l}14 \text { Depósitos de } \\
\text { infiltración }\end{array}$ & $\begin{array}{l}\text {-Estructuras que infiltran, retienen y } \\
\text { reutilizan el agua de escorrentía. } \\
\text {-Aumentan los recursos subterráneos, } \\
\text { recargan los acuíferos y disminuyen el } \\
\text { riesgo de inundación }\end{array}$ & $\begin{array}{l}\text { Profundidad: } 1,5 \mathrm{~m} \\
25<\text { talud }<35 \% \\
\text { Superficie recogida }>10 \text { ha }\end{array}$ & $\begin{array}{l}\text { Retención } \\
\text { Infiltración }\end{array}$ \\
\hline
\end{tabular}

Fuente: Elaboración propia a partir de RODRíGUEZ ROJAS, María Isabel. Guía para la Integración de los Sistemas Urbanos de Drenaje Sostenible en el Proyecto Urbano. Granada, Editorial Universidad de Granada, 2017. 


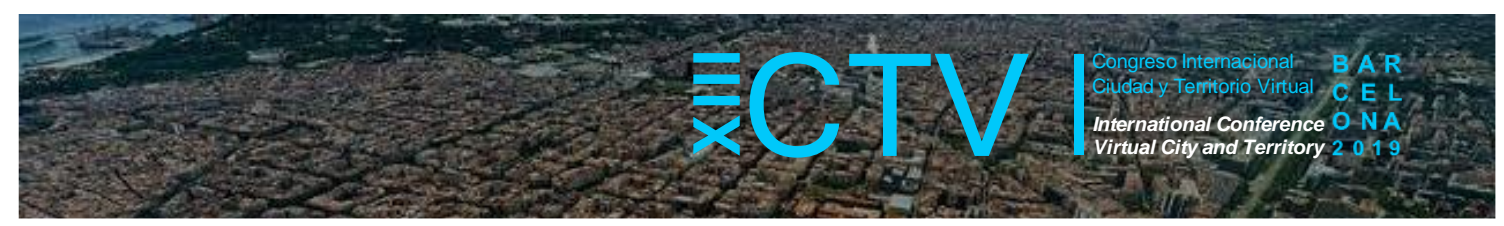

\subsubsection{Criterios urbanísticos ad-hoc}

En la zona de trabajo pueden adoptarse distintas acciones para reducir el riesgo de inundación y mitigación de los efectos del cambio climático en el área de Kjørbekk en función del tipo de elemento urbano, la propiedad, el uso y la cobertura del suelo.

Las ordenanzas pueden organizarse según las condiciones urbanas y formales de los elementos, realizando una primera división entre acciones vinculadas a elementos lineales y acciones vinculadas a elementos superficiales, tanto desde el punto de vista de gestión del agua (que incida sobre la sostenibilidad ambiental) como desde los criterios de sostenibilidad social y urbana del ámbito que favorezca un espacio público de calidad, con un paisaje con identidad y carácter propio que favorezca un modelo urbano cohesionado socialmente, donde se favorezcan las actividades económicas y se apueste por un modelo de crecimiento compacto que favorezca la regeneración de las superficies artificiales existentes y la eficiencia de los sistemas públicos.

\subsection{Medidas para la mitigacion del riesgo de inundación}

El trabajo de diagnostico y análisis de los usos, la propiedad y tipo de cobertura de los suelos del ámbito de trabajo, nos ha permitido observar algunas características especificas del área.

Puede hablarse de tres tipos fundamentales de suelo superficiales; aquellos vinculados a usos industriales de titularidad privada, con amplias zonas impermeabilizadas (zonas de aparcamiento y cubiertas), superficies de entre 0,5 y 2 ha aproximadamente; los parcelas residenciales privadas de menores dimensiones, con escasa impermeabilización del suelo (cubiertas y viario de acceso) y superficies entorno a los $500 \mathrm{~m} 2$; y suelos agrarios o forestales de grandes dimensiones, diversa propiedad y grados de escorrentía marcados fundamentalmente por la pendiente del terreno.

En función de estas tipologías complejas pueden establecerse unas medidas de actuación específicas, algunas ideas:

\section{A. ACCIONES VINCULADAS A ELEMENTOS DE CARÁCTER LINEAL:}

\section{A1. Encauzamiento}

Cauce principal.

Cauces secundarios.

A.2. Viario (según los tipos y propiedad de las vías)

2.1. Vías principales de carácter regional (tráfico pesado):

Acciones: Incrementar el arbolado público de alineación, franjas $>2 \mathrm{~m}$.

Localización de jardines de lluvia, zanjas filtrantes y estanques de retención ligados a franjas de protección, cunetas, medianas y elementos de tráfico, etc...

2.2. Vías locales estructurantes (tráfico pesado-transporte público):

Acciones:

Incrementar el arbolado público de alineación, franjas $<2 \mathrm{~m}$.

Fomentar el uso de cunetas verdes y zanjas de infiltración.

Localización de jardines de lluvia y estanques de retención ligados a lugares de uso público existentes en su recorrido (paradas de transporte público, parques, medianas y elementos de tráfico, etc... 


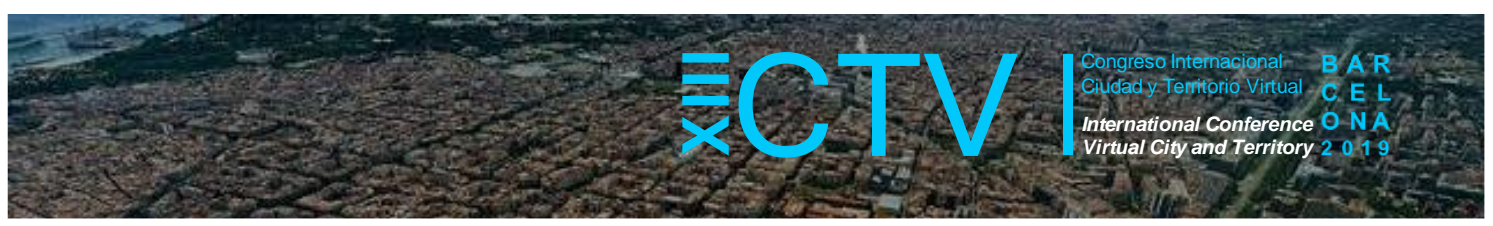

2.3 Vías locales (tráfico ligero):

Vías de acceso a parcela residenciales (tráfico ligero- esporádico y privado):

Acciones:

Sustitución de pavimentos impermeables por permeables.

Vías de acceso a parcela industriales (tráfico pesado -privado):

Acciones:

Drenes, franja de reserva $<1 \mathrm{~m}$.

A.3.Linderos:

Linderos de parcelas residenciales: barreras vegetales para la contención y filtrado del agua de escorrentía.

Linderos de parcelas industriales: barreras vegetales y definición de franjas verdes de la matriz natural.

B. ACCIONES VINCULADAS A ELEMENTOS DE CARÁCTER SUPERFICIAL: (todas las acciones dependerán del carácter del terreno, por lo que será necesario saber la formación y grado de contaminación del mismo mediante ensayos in situ).

- B1 Grandes pardelas industriales:

Acciones: encaminadas aumentar el grado de permeabilidad del suelo, disminuyendo la escorrentía superficial y las caudales puntas. Favorecer la implementación de zonas de retención y depuración del agua dentro de las propias parcelas. En las parcelas industriales de grandes dimensiones sería sencillo favorecer operaciones de adecuación ambiental del paisaje urbano que mejorasen la calidad urbana y favoreciesen la retención de agua, por ejemplo:

1 Incorporación de zonas ajardinadas en los linderos (elementos urbanos lineales),

diferenciando:

Nivel 1: franjas de vegetación de $<1,5 \mathrm{~m}$ de anchura, que favorezcan la continuidad de la matriz verde por contigüidad a otros elementos o frente al canal (amplificación de la infraestructura/parque inundable.

Acciones SuDS, ver tabla 3:03, 04, 08, 11.

Nivel2: franjas de vegetación de $1,5<\mathrm{a}<3 \mathrm{~m}$ de anchura, que favorezcan la continuidad de la matriz verde por contigüidad a otros elementos o frente al canal (amplificación de la infraestructura/parque inundable.

Acciones SuDS, ver tabla 3:03, 04, 06, 08.

Nivel3: franjas de vegetación de $>3 \mathrm{~m}$ de anchura, que favorezcan la continuidad de la matriz verde por contigüidad a otros elementos o frente al canal (amplificación de la infraestructura/parque inundable y generando zonas de retención, infiltración y depuración de agua.

Acciones SuDS, ver tabla 3:06, 12.

2 Picado o sustitución de un \% de suelo por pavimento permeable (áreas de estacionamiento).

Nivel 1: incrementar un $25 \%$ las superficies permeables de la parcela.

Acciones SuDS, ver tabla 3:07.

Nivel 2: incrementar un $50 \%$ las superficies permeables de la parcela.

Acciones SuDS, ver tabla 3:05.

Nivel 3: incrementar un $75 \%$ las superficies permeables de la parcela.

Acciones SuDS, ver tabla 3:09. 


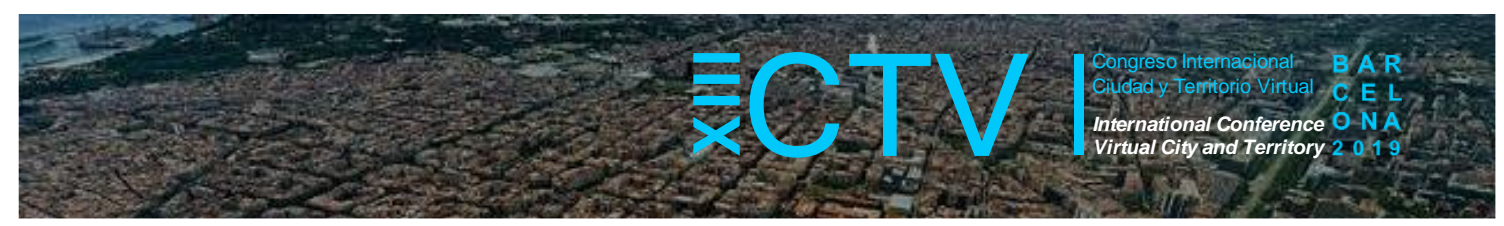

3 Actuaciones en las cubiertas, techos verdes

Nivel 1: incrementar un $50 \%$ las superficies permeables de cubierta.

Acciones SuDS, ver tabla 3:01.

Nivel 2: incrementar un $100 \%$ las superficies permeables de cubierta.

Acciones SuDS, ver tabla 3:01.

Nivel 3: incrementar entre un $50-100 \%$ las superficies permeables de cubierta y acumulación de agua.

Acciones SuDS, ver tabla 3:01 y 02.

- B2 Grandes parcelas terciario y equipamiento

Las grandes parcelas destinadas a usos terciarios y equipamientos. Asimilables a B1, pero con la importancia añadida de ser lugares donde puede favorecerse la vida urbana y la sociabilidad. Por otra parte, dentro del grupo de las grandes parcelas, los usos terciarios y educativos favorecen la actividad urbana de unos corredores frente a otros, pudiendo diferenciar entre prioritarios y secundarios. Añadiendo la posibilidad de por el uso público y constante de los mismo plantear la recogida de pluviales y la de aguas grises mediante depuración natural.

\section{- B3 Parcelas residenciales}

Las parcelas residenciales cuentan de medía con una parcela de menores dimensiones y débilmente urbanizadas. En muchos casos las parcelas en su lindero cuentan con un terraplén de tierra natural, parece razonable pensar que. aunque sea terreno privado pueden acometerse operaciones de canales abiertos para recoger el agua de las parcelas y viarios de acceso en estas franjas de terreno. La gran superficie ajardinada con la que cuentan la mayoría de parcelas permite fomentar la implementación de zonas de acumulación/depuración de agua dentro de las mismas.

Por otra parte, dentro del grupo de las grandes parcelas, los usos terciarios y educativos favorecen la actividad urbana de unos corredores frente a otros, pudiendo diferenciar entre prioritarios y secundarios. Añadiendo la posibilidad de por el uso público y constante de los mismo plantear la recogida de pluviales y la de aguas grises mediante depuración natural.

\section{- B4 Grandes parcelas agrícolas y B5 Grandes parcelas forestales}

Para B4 y B5, se trataría de controlar la permanencia de la cobertura vegetal, gestionar los vertidos al cauce (fertilizantes, purines, etc.) y proponer zonas de retención e infiltración de las pluviales.

Se definieron unas ordenanzas gráficas como herramienta de construcción de la matriz ambiental y social, con parámetros de forma según las dimensiones de las actuaciones recogidas en la tabla 3 y su posición (lindando con el canal, sobre los itinerarios peatonales e infraestructuras principales de drenaje superficial, en contigüidad a otras áreas, etc...).

En resumen, podemos decir que las medidas del grupo $(A)$ tienen por objetivos principales:

- el drenaje del terreno, su fin es recoger y transportar el agua, aunque en su traslado está puede retenerse, infiltrase y depurarse. 


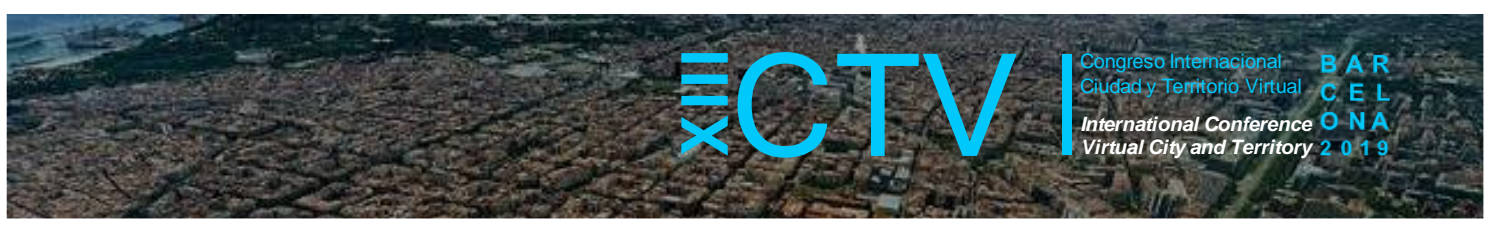

- la generación de un sistema de espacios públicos interrelacionados entre sí, con los lugares de sociabilidad (usos terciarios y educativos) y la matriz natural (cursos de aguas, parques existentes, canales y zonas naturales).

-la construcción de una matriz ambiental (medio físico, fauna y flora).

Mientras que los del grupo (B) son:

- el aumento de resiliencia del terreno, favoreciendo actuaciones que incidan sobre el coeficiente de escorrentía superficial (disminuyéndolo en aquellos suelos aptos-no contaminados).

- adecuación del paisaje urbano, generación de lugares de encuentro y nuevas actividades económicas.

- medidas de apoyo a la naturaleza (control de especies favorables y desfavorables de la fauna y flora).

\section{Figura 11. Esquema resumen de las acciones}

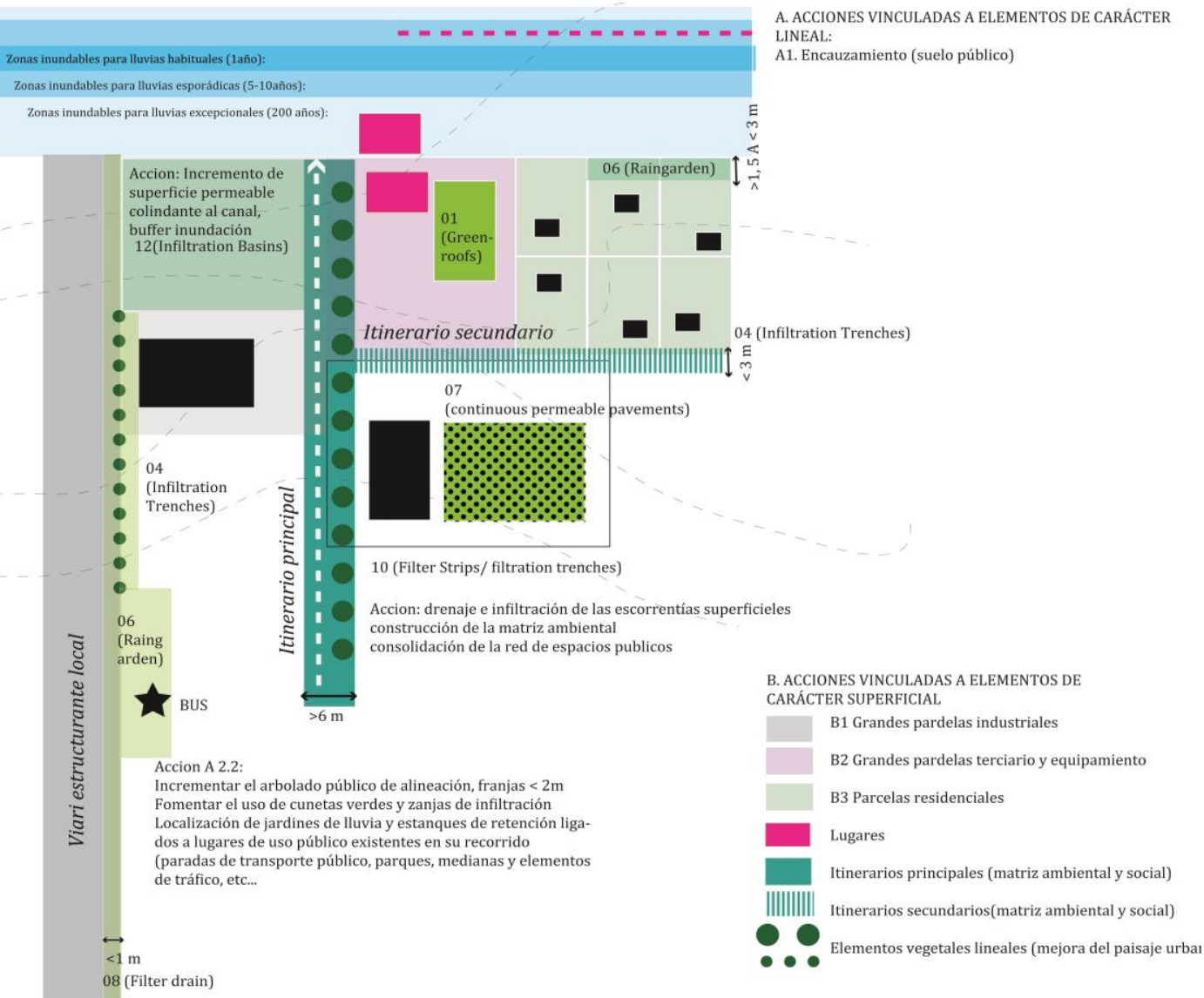

Fuente: Celia Martínez Hidalgo, 2018.

A modo de conclusión, consideramos que el caso de estudio muestra: la necesidad de planificar de manera conjunta la totalidad de usos y coberturas de la cuenca drenante, la complejidad para conocer y cohesionar el plano visible (superficial) y el invisible (subterráneo) en el proyecto urbano, la capacidad y oportunidad que suponen las infraestructuras de gestión del agua para construir un nuevo paisaje y mejorar el existente. 


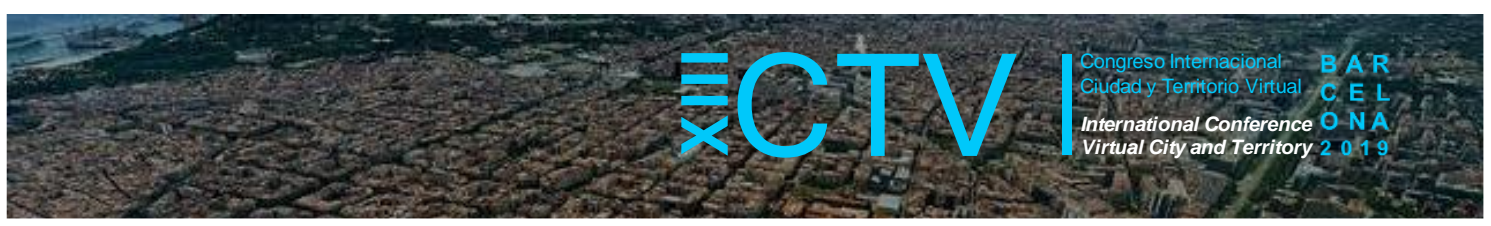

Figura 12. Fotomontaje de la intervencion con canal de aguas bajas y llanura de inundación

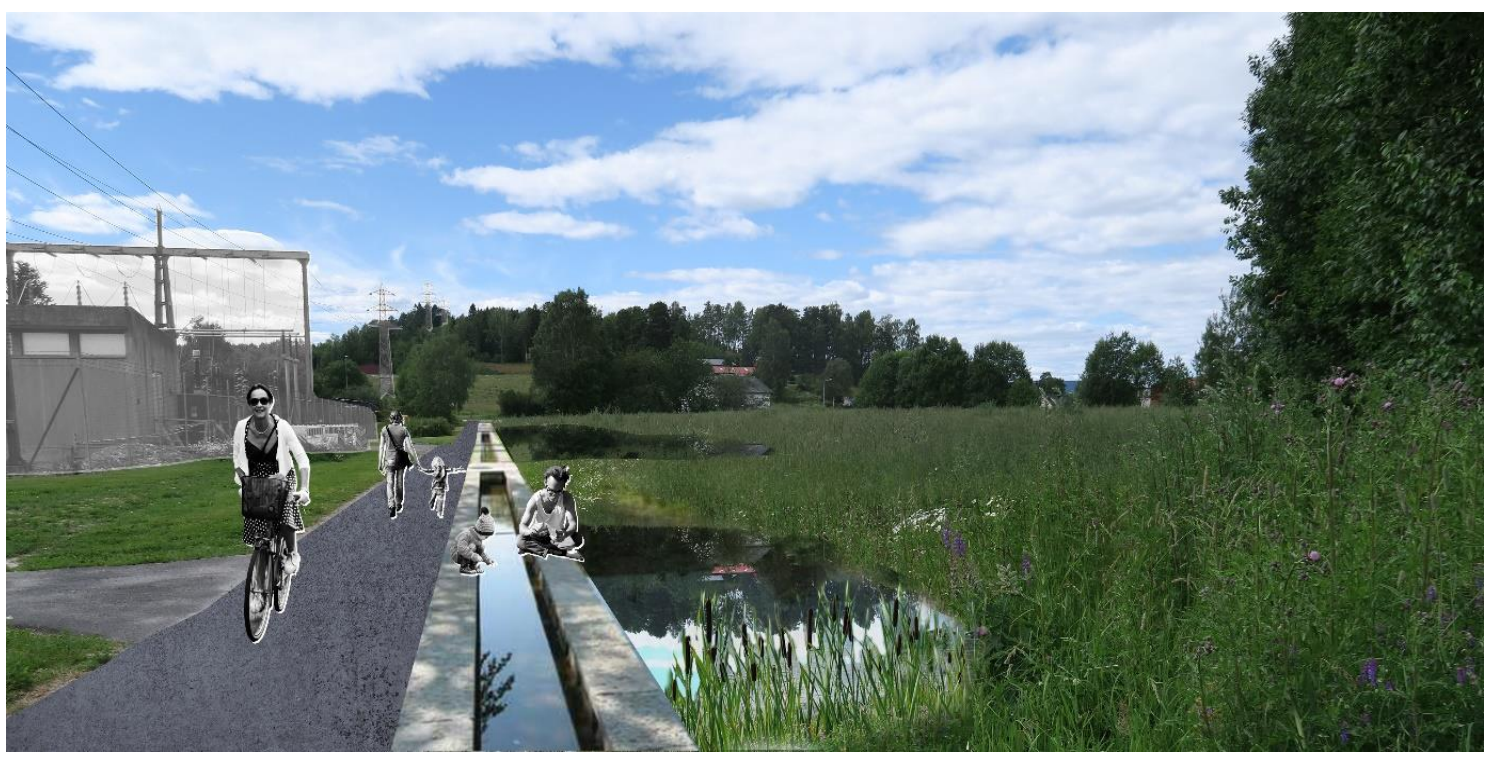

Fuente: Worksonland, 2018.

Conflicto de Intereses: Los autores declaran que no hay conflicto de intereses.

\section{Bibliografía}

Ajuntament de Barcelona. (29 de Enero de 2019). Informes del Institut Municipal d'Urbanisme. Recuperado de http://ajuntament.barcelona.cat/instituturbanisme/es

Centro de Estudios Ambientales. Ayuntamiento de Vitoria-Gasteiz. (2014). La infraestructura verde urbana de Vitoria-Gasteiz. Vitoria. Recuperado de https://www.vitoriagasteiz.org/docs/wb021/contenidosEstaticos/adjuntos/eu/32/95/53295.pdf

City of Copenhagen. (2014). Copenhagen: Solutions For Sustainable Cities. Copenhagen: City of Copenhagen. Recuperado de https://www.c40.org/case studies/copenhagen-solutions-forsustainable-cities

City of Melbourne. (29 de Enero de 2019). Guidelines for Water Sensitive Urban Design. Recuperado de Urban Water: http://urbanwater.melbourne.vic.gov.au/industry/wsud-guidelines

Department, B. T. (29 de Enero de 2019). Boston Complet Streets. Recuperado de:https://bostoncompletestreets.org/

Dobravolskaitè, R. (2010). Distribution patterns and ecological effect of invasive alien species Amelanchier spicata on the semi-natural forest communities in Lithuania. En Abstracts \& Excursion Guides del XXIII Conference-Expedition of the Baltic Botanist, Haapsalu, Estonia.

Fernández, J. (2000). Manual de Fitodepuración. Filtros de macrófitas en flotación. Madrid: Universidad Politécnica de Madrid. 


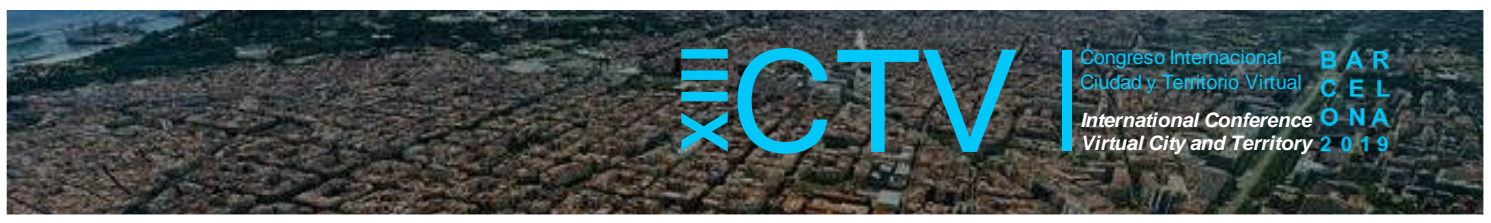

Fløistad I. S. (2010). Bekjempelse av kanadagullris. Kunnskapsblad fra FAGUS Rådgivning Nr. Noruega

Fylkesmannen i Oslo og Akershus (2010). Hagerømlinger - fra prydplanter til svartelistearter. Brosjyre. Et samarbeidsprosjekt mellom Fylkesmannen i Østfold, Fylkesmannen i Oslo og Akershus, Hageselskapet og Mattilsynet. Oslo, Noruega

Haga, K. (2017). De svartelistede plantene gror overalt. Recuperado de http://nab.no/nyheter/de-svartelistede-plantene-gror-overalt/19.15094

Heimstad, R. (2017). Kartlegging terrestrisk naturmiljø - Kjørbekk, Skien kommune, Kartlegging terrestrisk naturmiljø. Multiconsult.

Hlavínek, P., \& Zeleňáková, M. (2015). Storm Water Management. Examples from Czech Republic, Slovakia and Poland. Ed: Springer.

Ihobe, Sociedad Pública de Gestión Ambiental. (2019). 'Soluciones Naturales' para la adaptación al cambio climático en el ámbito local de la Comunidad Autónoma del País Vasco. Recuperado de Proyecto Klimatek 2016. Recuperado de http://www.euskadi.eus/contenidos/documentacion/soluciones naturales/es def/adjuntos/SOLU CIONESNATURALES.pdf

lowa Department of Agriculture and Land Stewardship. (2019). Urban Conservation Practices and Watershed Demonstration Projects. Recuperado de https://www.cleanwateriowa.org/urban-1/

Izembart, H., \& Le Boudec, B. (2003). Waterscapes: el tratamiento de aguas residuales mediante sistemas vegetales = using plant systems to treat wasterwater. Barcelona: Gustavo Gili.

KInder, K. (2015). The politics of urban water: changing waterscapes in Amsterdam. Athens: The University of Georgia Press.

Magrini, C., \& López Varela, S. (2018). Valparaíso H30. Humedad y restauración ecológica: estrategias para un ordenamiento territorial desde sus factores de riesgo. En Revistas Electrónicas UACh. Recuperado de http://mingaonline.uach.cl/scielo.php?pid=S0718$\underline{72622016000100004 \& \text { script }=\text { sci arttext }}$

Organización de las Naciones Unidas para la alimentación y la agricultura. (2019). FAO. Captación y almacenamiento de agua de lluvia. Opciones técnicas para la agricultura familiar en América Latina y el Caribe. Recuperado de http://www.fao.org/docrep/019/i3247s/i3247s.pdf

Rodríguez Rojas, M. (2017). Guía para la integración de los sistemas urbanos de drenaje sostenible en el proyecto urbano. Granada: Universidad de Granada.

Rueda, S. (2012). Libro verde de sostenibilidad urbana y local en la era de la información. Madrid: Ministerio de Agricultura, Alimentación y Medio Ambiente. 